Supplemental Information for

\title{
Macromolecular Photocatalyst for Synthesis and Purification of Protein-Polymer Conjugates
}

Rebecca A. Olson, Jordan S. Levi, Georg M. Scheutz, Jacob J. Lessard, C. Adrian Figg, Manasi N. Kamat, Kari B. Basso, Brent S. Sumerlin*

George \& Josephine Butler Polymer Research Laboratory, Center for Macromolecular Science \& Engineering, Department of Chemistry, University of Florida, PO Box 117200, Gainesville, FL 32611-7200, United States

\section{Contents}

Materials. 3

Chemicals. 3

Instrumentation 3

Nuclear Magnetic Resonance spectroscopy (NMR) ........................................................... 3

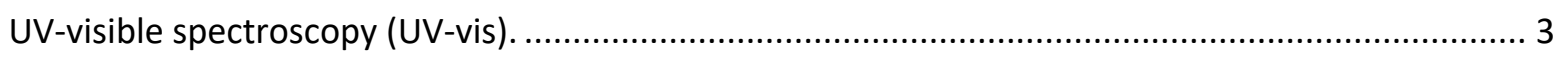

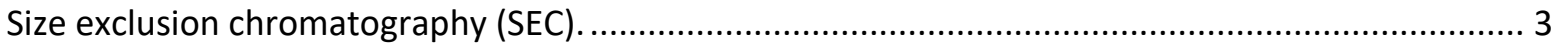

Matrix-Assisted Laser Desorption/Ionization Mass Spectrometry (MALDI). ................................... 4

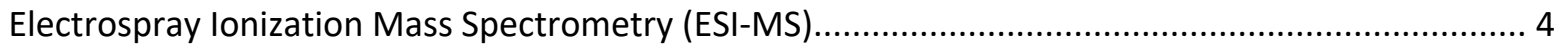

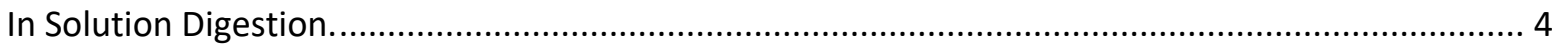

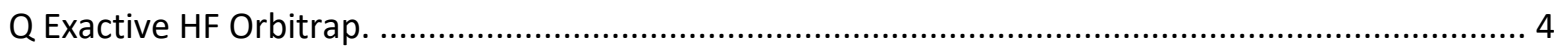

Sodium Dodecyl Sulfate-Polyacrylamide Gel Electrophoresis (SDS-PAGE Gel). .............................. 6

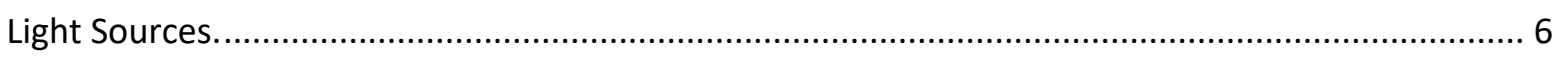

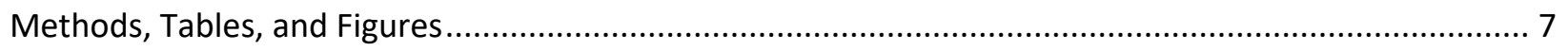

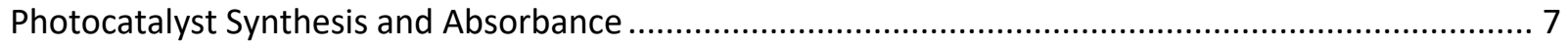

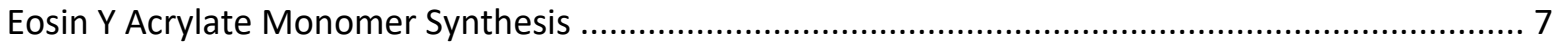

Synthesis of Poly(Eosin Y Acrylate-co-NIPAAm) p(EY-NIPAAm) Photocatalyst.................................. 8

Eosin Y Methyl Ester (EYMe) UV-vis Absorbance Assay in DMSO ............................................... 9

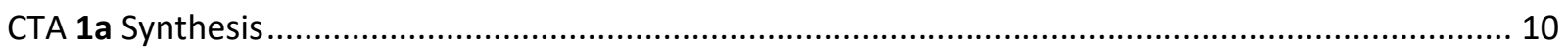

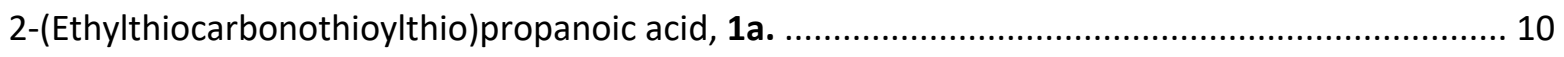

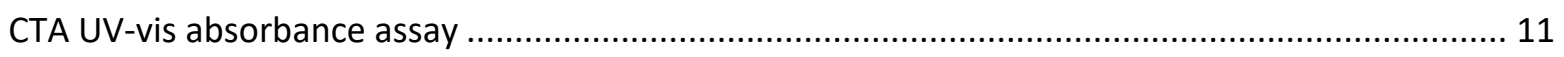

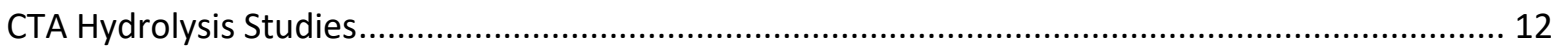

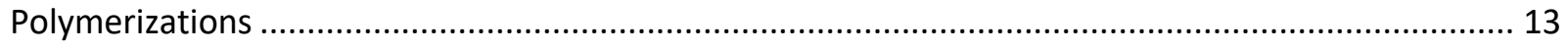

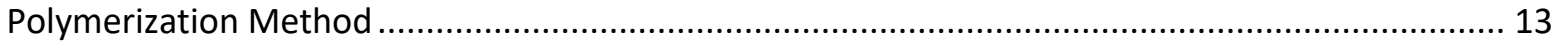

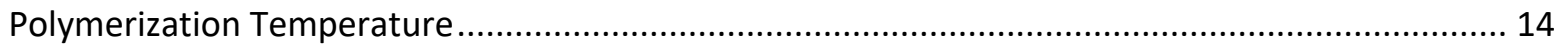

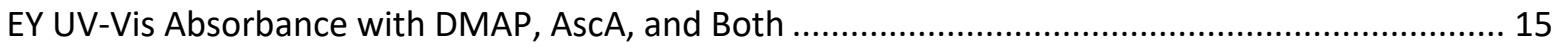




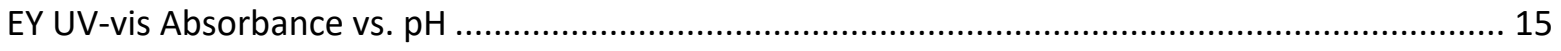

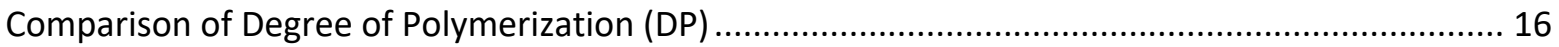

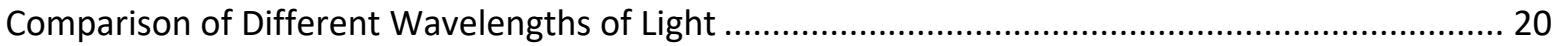

UV-vis Absorbance of p(EY-NIPAAm) compared to EY in Polymerization Solution .......................... 21

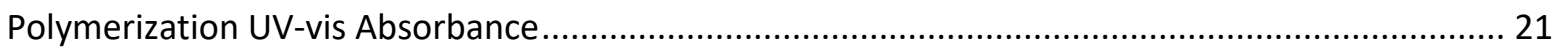

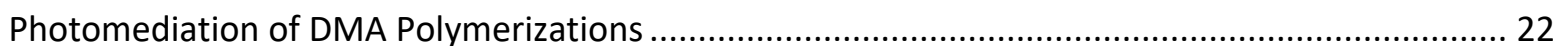

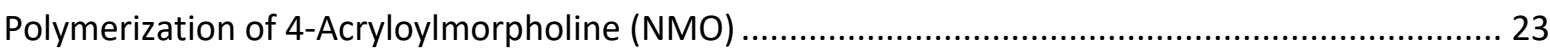

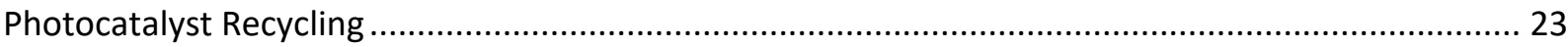

Maleimide Functional Chain Transfer Agent (CTA) Synthesis......................................................... 26

4,10-Dioxatricyclo[5.2.1. $0^{2,6}$ ]dec-8-ene-3,5-dione, 2a.......................................................... 26

4-(2-Hydroxyethyl)-10-oxa-4-azatricyclo[5.2.1.0 ${ }^{2,6}$ ]dec-8-ene-3,5-dione, 2b................................ 27

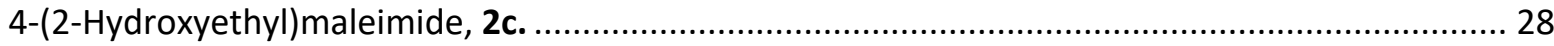

2-(((Ethylthio)carbonothioyl)thio)propanoate-4-(2-hydroxyethylmaleimide) 1. ............................ 28

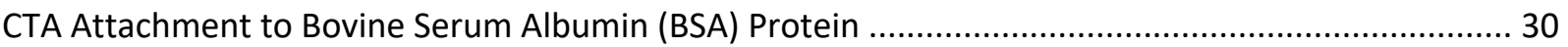

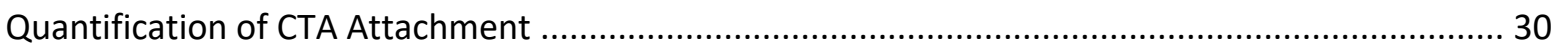

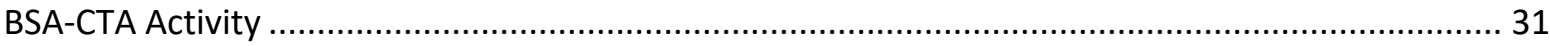

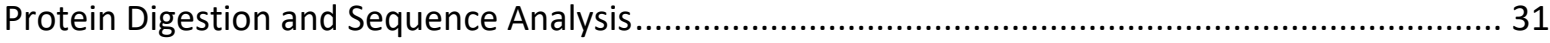

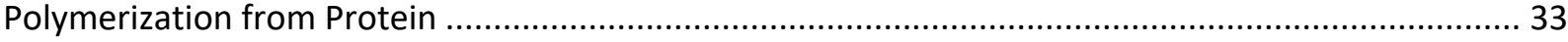

Control Polymerization of DMA with EY from Protein.................................................................... 34

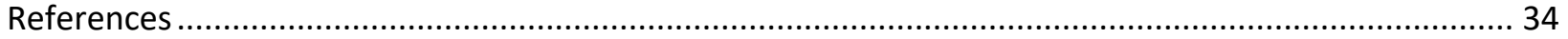




\section{Materials}

\section{Chemicals}

All reagents were obtained from commercial sources and used as received unless otherwise noted. The following chemicals were obtained from Sigma Aldrich: acrylamide (Electrophoresis Grade, 99+\%), 4acryloylmorpholine (NMO, 97\%), L-ascorbic acid (AscA, 99\%), 2-bromopropionic acid (99\%), ethanolamine (99\%), $N, N$-dimethylacetamide (DMAc, 99\%), $N, N^{\prime}$-dimethylacrylamide (DMA, 99\%), ethanethiol (97\%), $\mathrm{N}, \mathrm{N}$-diisopropylethylamine (DIPEA, 99+\%), 1,4-dithiothreitol (DTT, 98+\%), furan (99+\%), 2-hydroxyethyl acrylate (HEA, 96\%), $N$-hydroxysuccinimide (NHS, 98\%), $N$-isopropylacrylamide (NIPAAm, 97\%), N,N, $N^{\prime}, N^{\prime}$ tetramethylethylenediamine (99\%), and trifluoroacetic acid (TFA, 99\%). The following chemicals were obtained from Fisher: acetic acid (AcOH, ACS Grade), acetone (ACS Grade), carbon disulfide (ACS Grade), dimethyl sulfoxide (DMSO, ACS Grade), magnesium sulfate anhydrous ( $\mathrm{MgSO}_{4}$, Certified), methanol ( $\mathrm{MeOH}, \mathrm{ACS}$ Grade), methylene chloride (DCM, Fisher, ACS Grade), potassium hydroxide (KOH, ACS Grade), sodium bicarbonate ( $\mathrm{NaHCO}_{3}, \mathrm{ACS}$ Grade), sodium hydroxide ( $\mathrm{NaOH}, \mathrm{ACS}$ Grade), and toluene (ACS Grade). The following chemicals were obtained from VWR: N,N-dimethylformamide (DMF, ACS Grade) and hydrochloric acid ( $\mathrm{HCl}, \mathrm{ACS}$ Grade). Deuterated chloroform $\left(\mathrm{CDCl}_{3}, 99.8 \%\right.$ with $\left.0.05 \% \mathrm{v} / \mathrm{v} \mathrm{TMS}\right)$ and dimethyl sulfoxide (DMSO- $d_{6}, 99.9 \%$ with $0.05 \% \mathrm{v} / \mathrm{v}$ TMS) were obtained from Cambridge Isotope Laboratories, Inc. Other chemicals included ammonium persulfate (Acros Organics, 98+\%), Coomassie Brilliant Blue G-250 (Thermo Scientific), 4-(dimethylamino)pyridine (DMAP, EMD Millipore Corporation), 3,5-dimethoxy-4-hydroxycinnamic acid (sinapinic acid, Indofine Chemical Company, 99\%), eosin Y (EY, Santa Cruz Biotechnology), 1-(3-dimethylaminopropyl)-3-ethylcarbodiimide hydrochloride (EDC.HCl, Oakwood Chemical, 99\%), hydrazine monohydrate (Alfa Aesar, 98+\%), maleic anhydride (Alfa Aesar, $98+\%), N, N^{\prime}$-methylenebisacrylamide (Alfa Aesar, 97\%), 4-nitrophenyl acetate (4NPA, Alfa Aesar, 98+\%), sodium phosphate dibasic (J.T. Baker, Ultrapure Bioreagent), sodium phosphate monobasic (J.T. Baker, Ultrapure Bioreagent), tetrahydrofuran (THF, Avantor, ACS Grade), and triethylamine (TEA, Acros Organics, 99\%). Type 1 ultrapure water was obtained using the Millipore Synergy UV-R water purification system. Dry solvents were passed through two activated alumina columns in the MBRAUN solvent purification system. DMA and NMO were run through a plug of basic alumina prior to polymerization. NIPAAm was recrystallized from methanol prior to polymerization.

\section{Instrumentation}

Nuclear Magnetic Resonance spectroscopy (NMR). ${ }^{1} \mathrm{H}$ NMR and ${ }^{13} \mathrm{C}$ NMR spectra were obtained using a Bruker $400 \mathrm{MHz}$ NMR spectrometer, a Bruker $600 \mathrm{MHz}$, or a Varian Inova2 $500 \mathrm{MHz}$ NMR spectrometer. Tri(methylsilyl)silane (TMS) or residual solvent was used as a reference.

UV-visible spectroscopy (UV-vis). UV-vis spectra were obtained on the Molecular Devices SpectraMax M2 multimode microplate reader with samples in a clear polypropylene 96-well plate (Greiner Bio-One).

Size exclusion chromatography (SEC). The reported molecular weights and molecular weight distributions were obtained in DMAc with $50 \mathrm{mM} \mathrm{LiCl}$ at $50{ }^{\circ} \mathrm{C}$ flowing at a rate of $1.0 \mathrm{~mL} / \mathrm{min}$ (Agilent isocratic pump, degasser, and autosampler). The columns consisted of a ViscoGel guard column and two ViscoGel I-series G3078 mixed bed columns. The molecular weight ranges were 0-20,000 Da and 01,000,000 Da. Detection was carried out with a Wyatt Optilab T-rEX detector operating at $658 \mathrm{~nm}$. Molecular weights were obtained using conventional calibration with poly(methyl methacrylate) standards. 
Matrix-Assisted Laser Desorption/Ionization Mass Spectrometry (MALDI).

Spectra were obtained on a Bruker Autoflex LRF MALDI-ToF/ToF operated in reflectron, positive ion mode using the pulsed smartbeam-II UV laser ( $355 \mathrm{~nm}$ ). The minimal laser intensity necessary to generate a reliable signal was used. The instrument can resolve molecules up to 20,000 Da in reflectron mode and was calibrated with Peptide Calibration Standard II purchased from Bruker Daltonics. This mixture covers a mass range of $700-3200$ Da with peptides Angiotensin II, Angiotensin I, Substance P, Bombesin, ACTH clip 1-17, ACTH clip 18-39, Somatostatin 28, Bradykinin Fragment 1-7, Renin Substrate Tetradecapeptide porcine.

The protein samples were prepared by combining sinapinic acid $\left(20 \mathrm{mg} / \mathrm{mL}\right.$ in v:v $1: 1$ mix of ACN: $\mathrm{H}_{2} \mathrm{O}$ with $1 \%$ TFA) with the protein ( $1 \mathrm{mg} / \mathrm{mL}$ in v:v $1: 1$ mix of $A C N: \mathrm{H}_{2} \mathrm{O}$ with $1 \%$ TFA) in a $5: 2$ v:v ratio (matrix:polymer). Samples (1-2 $\mu \mathrm{L}$ ) were spotted on the polished stainless steel Bruker plate. The mixtures were dried under ambient conditions.

Electrospray Ionization Mass Spectrometry (ESI-MS).

Electrospray ionization spectra were obtained using an Agilent 6220 Time-of-Flight ESI in positive ion mode. The gas temperature was $350^{\circ} \mathrm{C}$. The nitrogen drying gas flowed at a rate of $8.0 \mathrm{~L} / \mathrm{min}$, and the nebulizer pressure was 30 psi. The injection system was a Agilent 1100 series system consisting of a G13793 degasser, a G1312B binary pump, and a G1367C auto sampler. The injection volume was $1 \mu \mathrm{L}$. The mobile phase was methanol with $0.1 \%$ formic acid. The flow rate was $0.2 \mathrm{~mL} / \mathrm{min}$. The sample was dissolved in chloroform $(5 \mu \mathrm{L})$ and diluted in methanol $(1 \mathrm{~mL})$ prior to injection.

In Solution Digestion.

Total protein was determined on a Qubit, and the appropriate volume of each sample was taken to equal $8 \mu \mathrm{g}$ total protein for digestion. The samples were digested with a sequencing grade trypsin/lys $\mathrm{C}$ rapid digestion kit from Promega (Madison WI) using the manufacturer recommended protocol. Three times the sample volume of rapid digestion buffer (provided with the kit) was added to the samples. The sample was incubated at $56{ }^{\circ} \mathrm{C}$ with DTT $(1 \mu \mathrm{l})$ solution $(0.1 \mathrm{M}$ in $100 \mathrm{mM}$ ammonium bicarbonate) for $30 \mathrm{~min}$ prior to the addition of lodoacetamide $(0.54 \mu \mathrm{L}$ of $55 \mathrm{mM}$ solution in $100 \mathrm{mM}$ ammonium bicarbonate). lodoacetamide was incubated at room temperature in the dark for $30 \mathrm{~min}$. The trypsin/lys C ( $1 \mu \mathrm{g} / \mu \mathrm{l})$ was prepared fresh in the rapid digestion buffer. Enzyme $(1 \mu \mathrm{L})$ was added, and the samples were incubated at $70{ }^{\circ} \mathrm{C}$ for $1 \mathrm{~h}$. The digestion was stopped by addition of $0.5 \%$ TFA. MS analysis was immediately performed to ensure high quality tryptic peptides with minimal non-specific cleavage.

\section{Q Exactive HF Orbitrap.}

Nano-liquid chromatography tandem mass spectrometry (Nano-LC/MS/MS) was performed on a Thermo Scientific Q Exactive HF Orbitrap mass spectrometer equipped with an EASY Spray nanospray source (Thermo Scientific) operated in positive ion mode. The LC system was an UltiMate ${ }^{\text {TM }} 3000$ RSLCnano system from Thermo Scientific. The mobile phase $A$ was water containing $0.1 \%$ formic acid and the mobile phase B was acetonitrile with $0.1 \%$ formic acid. The volume of injection was calculated for each sample such that that $0.2 \mu \mathrm{g}$ of sample was injected onto a Thermo Fisher Scientific Acclaim Trap Cartridge (C18 column, 75 um ID, 2 cm length, $3 \mu \mathrm{m} 100 \AA$ pore size) at a $25 \mu \mathrm{L} / \mathrm{ml}$ flow rate. This flow rate was held for 10 min and washed with $2 \%$ mobile phase $B$ to desalt and concentrate the peptides. The peptides were injected and eluted off of the trap onto the column. An EASY Spray PepMAP column from Thermo Scientific was used for chromatographic separations (C18, $75 \mu \mathrm{m} I D, 25 \mathrm{~cm}$ length, $3 \mu \mathrm{m}$, $100 \AA$ pore size). The column temperature was maintained at $35^{\circ} \mathrm{C}$. Peptides were eluted directly off of the column 
into the $Q$ Exactive system using the following gradient:

\begin{tabular}{|l|l|}
\hline Time (min) & \% mobile phase B \\
\hline 0 & 2 \\
\hline 10 & 2 \\
\hline 20 & 7 \\
\hline 240 & 45 \\
\hline 250 & 80 \\
\hline 255 & 80 \\
\hline 256 & 2 \\
\hline 260 & 2 \\
\hline
\end{tabular}

The total run time was $260 \mathrm{~min}$. The MS/MS was acquired according to standard conditions established in the lab. The EASY Spray source operated with a spray voltage of $1.5 \mathrm{KV}$ and a capillary temperature of $200{ }^{\circ} \mathrm{C}$. The scan sequence of the mass spectrometer was based on the original TopTen ${ }^{\mathrm{TM}}$ method; the analysis was programmed for a full scan recorded between 375 - 1575 Da at 60,000 resolution and a MS/MS scan at resolution 15,000 to generate product ion spectra to determine amino acid sequence in consecutive instrument scans of the fifteen most abundant peaks in the spectrum. The AGC Target ion number was set at $3 \times 10^{6}$ ions for full scan and $2 \times 10^{5}$ ions for $\mathrm{MS}^{2}$ mode. Maximum ion injection time was set at 50 ms for full scan and 55 ms for MS $^{2}$ mode. Micro scan number was set at 1 for both full scan and $M^{2}$ scan. The HCD fragmentation energy (N)CE/stepped NCE was set to $28 \mathrm{eV}$. Singly charged ions were excluded from $\mathrm{MS}^{2}$. Dynamic exclusion was enabled with a repeat count of 1 within $30 \mathrm{~s}$ and set to exclude isotopes. A Siloxane background peak at 445.12003 Da was used as the internal lock mass.

HeLa protein digest standard was used to evaluate the integrity and the performance of the columns and mass spectrometer. If the number of protein IDs from the HeLa standard fell below 2700 , the instrument was cleaned, and new columns were installed.

Database Searching. All MS/MS samples were analyzed using Sequest (XCorr Only) (Thermo Fisher Scientific, San Jose, CA, USA; version IseNode in Proteome Discoverer 2.2.0.388). Sequest (XCorr Only) was set up to search Homo sapiens (SwissProt TaxID=9606_and_subtaxonomies) (v2018-02-28 42253 entries) assuming the digestion enzyme trypsin. Sequest (XCorr Only) was searched with a fragment ion mass tolerance of $0.020 \mathrm{Da}$ and a precursor ion tolerance of $10.0 \mathrm{ppm}$. Carbamidomethyl of cysteine was specified in Sequest (XCorr Only) as a fixed modification. Deamidated of asparagine and oxidation of methionine were specified in Sequest (XCorr Only) as variable modifications.

Criteria for Protein Identification. Scaffold (version Scaffold_4.9.0, Proteome Software Inc., Portland, OR) was used to validate MS/MS based peptide and protein identifications. Peptide identifications were accepted if they could be established at greater than $95.0 \%$ probability by the Peptide Prophet algorithm with Scaffold delta-mass correction. ${ }^{1}$ Protein identifications were accepted if they could be established at greater than $99.0 \%$ probability and contained at least 1 identified peptide. Protein probabilities were assigned by the Protein Prophet algorithm. ${ }^{2}$ Proteins that contained similar peptides and could not be differentiated based on MS/MS analysis alone were grouped to satisfy the principles of parsimony. Proteins sharing significant peptide evidence were grouped into clusters. 
Sodium Dodecyl Sulfate-Polyacrylamide Gel Electrophoresis (SDS-PAGE Gel).

Polyacrylamide gels (5 wt\%, 30:0.8 acrylamide:methylene bisacrylamide) were run in a Mini-PROTEAN electrophoresis system (Biorad). Samples were prepared in a denaturing buffer and heated $10 \mathrm{~min}$ at $100{ }^{\circ} \mathrm{C}$ to denature proteins. The gel was run at $180 \mathrm{~V}$ for $90 \mathrm{~min}$ to separate the proteins prior to visualization with a Coomassie Blue stain.

\section{Light Sources.}

Photoreactors were built according to a literature procedure. ${ }^{3}$ The blue light had a maximum emission at $458 \mathrm{~nm}$ and an intensity of $0.6 \mathrm{~mW} / \mathrm{cm}^{2}$. The green light had a maximum emission at $515 \mathrm{~nm}$ and an intensity of $0.5 \mathrm{~mW} / \mathrm{cm}^{2}$. The yellow light had a maximum emission at $597 \mathrm{~nm}$ and an intensity of 0.1 $\mathrm{mW} / \mathrm{cm}^{2}$. The normalized lamp emission spectra are shown below.

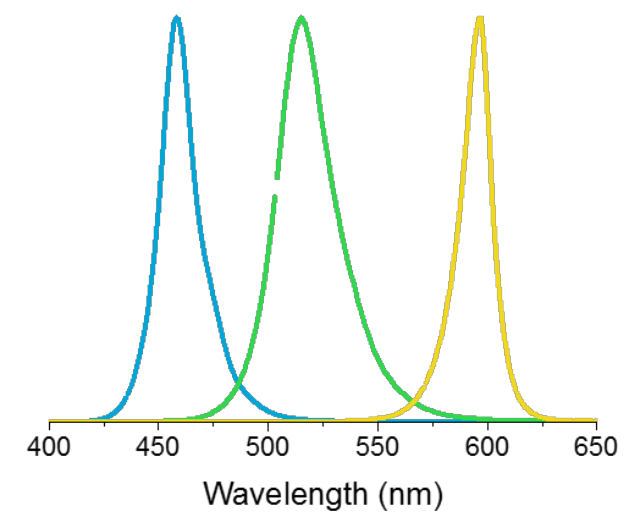

Figure S1: Normalized UV-vis emission spectra of blue, green, and yellow light sources. 


\section{Methods, Tables, and Figures}

\section{Photocatalyst Synthesis and Absorbance}

Eosin Y Acrylate Monomer Synthesis

$\mathrm{EY}(0.500 \mathrm{~g}, 0.772 \mathrm{mmol}), \operatorname{DMAP}(0.028 \mathrm{~g}, 0.23 \mathrm{mmol})$, and EDC $\cdot \mathrm{HCl},(0.444 \mathrm{~g}, 2.32 \mathrm{mmol})$ were combined in a flame-dried round bottom flask under argon. At $0{ }^{\circ} \mathrm{C}$, dry DMF $(4 \mathrm{~mL})$ was added together with 2hydroxyethyl acrylate $(0.279 \mathrm{~g}, 2.32 \mathrm{mmol})$ and TEA $(0.078 \mathrm{~g}, 0.77 \mathrm{mmol})$. The reaction was stirred overnight and warmed up to room temperature. Upon dilution with $\mathrm{DCM}$, the crude mixture was washed with aqueous $\mathrm{HCl}(1 \mathrm{M}), \mathrm{NaHCO}_{3}$ (saturated), water and brine. After drying the organic extract with $\mathrm{MgSO}_{4}$, the solvent was evaporated, and the compound was purified by flash column chromatography on silica gel with DCM/AcOH (97/3 v/v).

$0.415 \mathrm{~g}$ (0.556 mmol; $72 \%$ yield)

$\mathrm{R}_{f} \sim 0.3$ in $\mathrm{DCM} / \mathrm{AcOH}(97 / 3 ; \mathrm{v} / \mathrm{v})$

${ }^{1} \mathrm{H}$ NMR $\left(500 \mathrm{MHz}\right.$, DMSO- $\left.d_{6}\right) \delta 8.24(\mathrm{~d}, J=7.9 \mathrm{~Hz}, 1 \mathrm{H}), 7.91(\mathrm{~m}, 1 \mathrm{H}), 7.84(\mathrm{~m}, 1 \mathrm{H}), 7.51(\mathrm{~d}, J=7.6 \mathrm{~Hz}, 1 \mathrm{H})$, $7.10(\mathrm{~s}, 2 \mathrm{H}), 6.18(\mathrm{~d}, J=17.1 \mathrm{~Hz}, 1 \mathrm{H}), 5.93(\mathrm{dd}, J=17.1,10.3 \mathrm{~Hz}, 1 \mathrm{H}), 5.83(\mathrm{~d}, J=10.4 \mathrm{~Hz}, 1 \mathrm{H}), 4.26(\mathrm{~m}, 2 \mathrm{H})$, $4.20(\mathrm{~b}, \mathrm{OH}), 4.04(\mathrm{~m}, 2 \mathrm{H})$

${ }^{13} \mathrm{C}$ NMR $\left(125 \mathrm{MHz}\right.$, DMSO- $\left.d_{6}\right) \delta 165.1,164.8,164.7,152.2,151.0,133.7,132.5,131.9,131.3,130.8,130.2$, $129.3,127.5,117.3,115.5,100.3,63.3,62.2$

HRMS (ESI-TOF): Calculated for $[\mathrm{M}+\mathrm{H}]^{+}$requires 746.7502 ; found 746.7499.
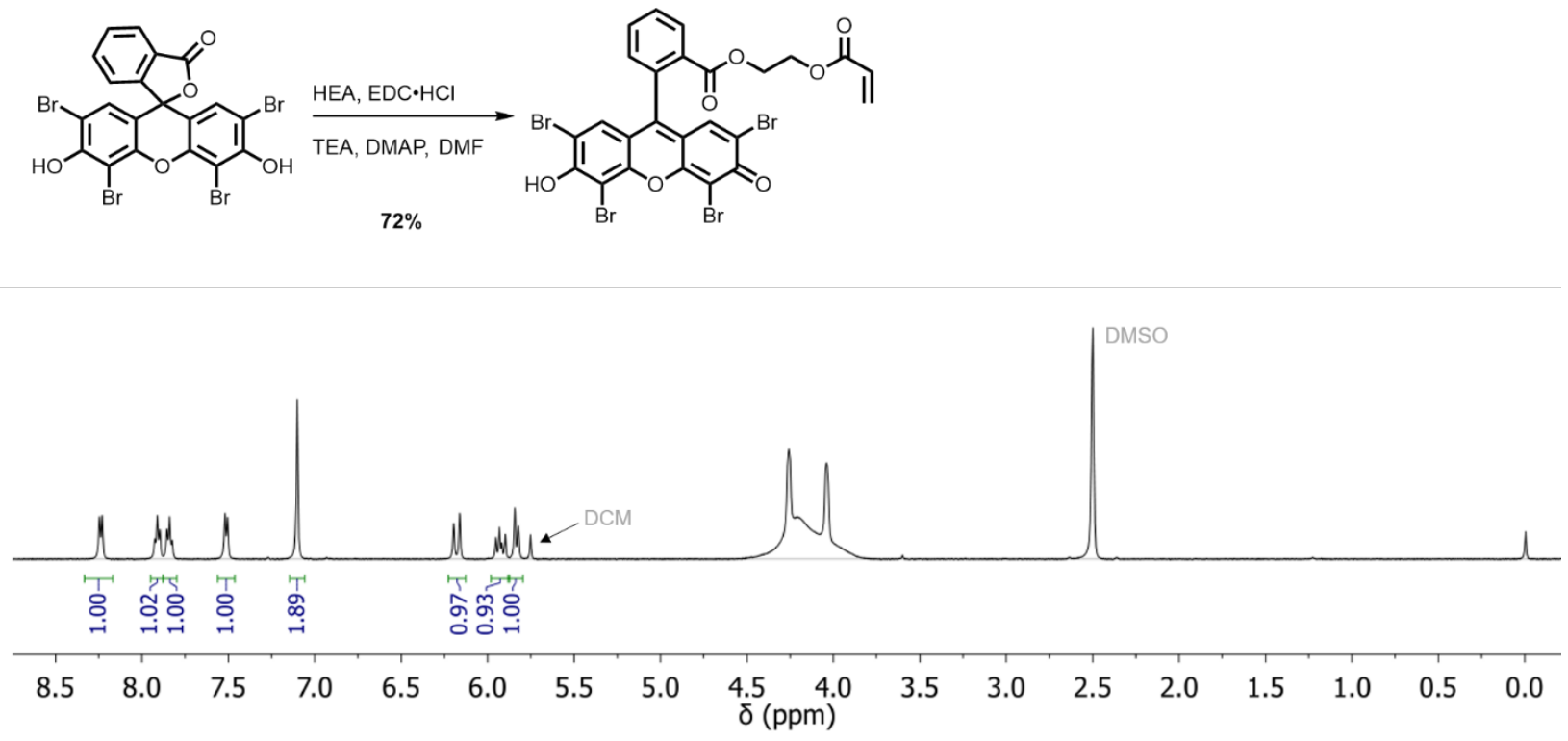

Figure S2: ${ }^{1} H$ NMR spectrum of eosin Y acrylate in DMSO-d $d_{6}$. 


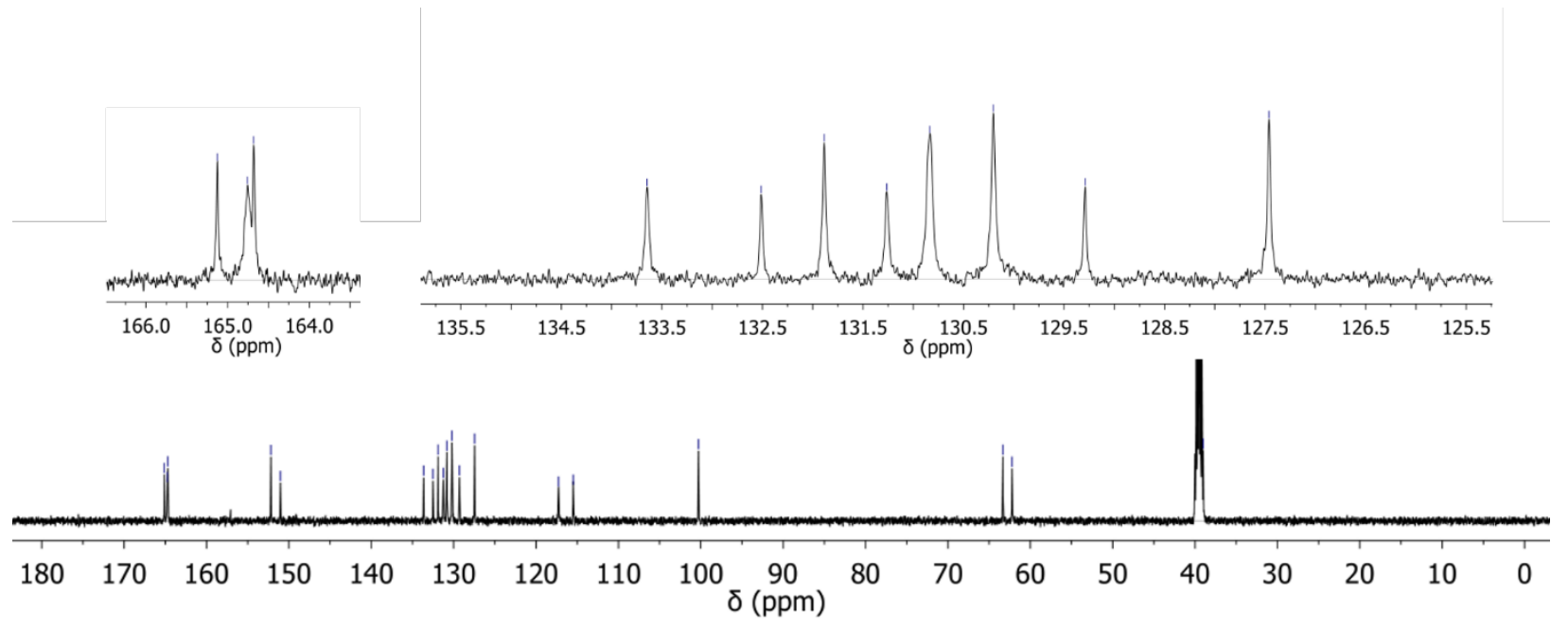

Figure S3: ${ }^{13} \mathrm{C} N M R$ spectrum of eosin Y acrylate in DMSO- $d_{6}$.

Synthesis of Poly(Eosin Y Acrylate-co-NIPAAm) p(EY-NIPAAm) Photocatalyst

2-(Dodecylthiocarbonothioylthio)-2-methylpropionic acid $(9.0 \mathrm{mg}, 0.024 \mathrm{mmol})$, NIPAAm (2.0005 g, $17.678 \mathrm{mmol})$, eosin $\mathrm{Y}$ acrylate $(9.9 \mathrm{mg}, 0.013 \mathrm{mmol})$, and DMAP $(2.8 \mathrm{mg}, 0.023 \mathrm{mmol})$ were dissolved in a solution of DMSO (3.47 mL, $5 \mathrm{M}$ solution) with DMF $(50 \mu \mathrm{L})$ as an internal standard for ${ }^{1} \mathrm{H}$ NMR. The solution was sparged in the dark, and then the reaction was initiated by irradiation with green light. The light was turned off when the reaction reached a final conversion of $72 \%$. The mixture was precipitated into cold diethyl ether and dried under vacuum (yield $=1.51 \mathrm{~g}, 105 \%$ yield).

The copolymer (1.5116 g, $0.019183 \mathrm{mmol})$ was dissolved in DMF $(3.0 \mathrm{~mL})$ in a 10-mL Schlenk flask. The reaction was sparged with argon for $20 \mathrm{~min}$. Hydrazine monohydrate $(74 \mu \mathrm{L}, 76 \mathrm{mg}, 1.5 \mathrm{mmol}$ ) in DMF $(0.50 \mathrm{~mL})$ was added from a degassed syringe. The reaction was stirred for 30 min prior to addition of DMA (1.6 mL, $1.5 \mathrm{~g}, 15 \mathrm{mmol})$. The reaction was stirred overnight (>16 h). The reaction mixture was precipitated into cold diethyl ether and dialyzed (Spectrum $50 \mathrm{kDa}$ cutoff regenerated cellulose tubing) for three days against DI water ( $13 \mathrm{~L}$ ) to remove any residual monomer ( $1.0 \mathrm{~g}, 69 \%$ yield).

A known mass of $p$ (EY-NIPAAm) was dissolved in DMSO, and the UV-vis absorbance intensity was compared with the eosin $\mathrm{Y}$ methyl ester concentration curve (vide infra) to determine the number of eosin $Y$ acrylate monomers incorporated per polymer chain. This analysis indicated 0.26 eosin $Y$ acrylate residues were incorporated per polymer chain, or approximately one in four chains had an eosin Y acrylate monomer unit. When the equivalents of $p(E Y-N I P A A m)$ are listed, the equivalents refer to the equivalents of eosin $\mathrm{Y}$ acrylate. The molecular weight of NIPAAm per eosin $\mathrm{Y}$ acrylate is $309,000 \mathrm{~g} / \mathrm{mol}$. Precipitation and recovery of the photocatalyst is best realized with an appreciable amount of thermoresponsive polymer. Due to the small sample volumes, a lower loading of eosin $Y$ acylate was incorporated such that a sufficient amount of thermoresponsive polymer is present in each reaction to facilitate removal.

The polymeric photocatalyst was stored in the dark until use. 

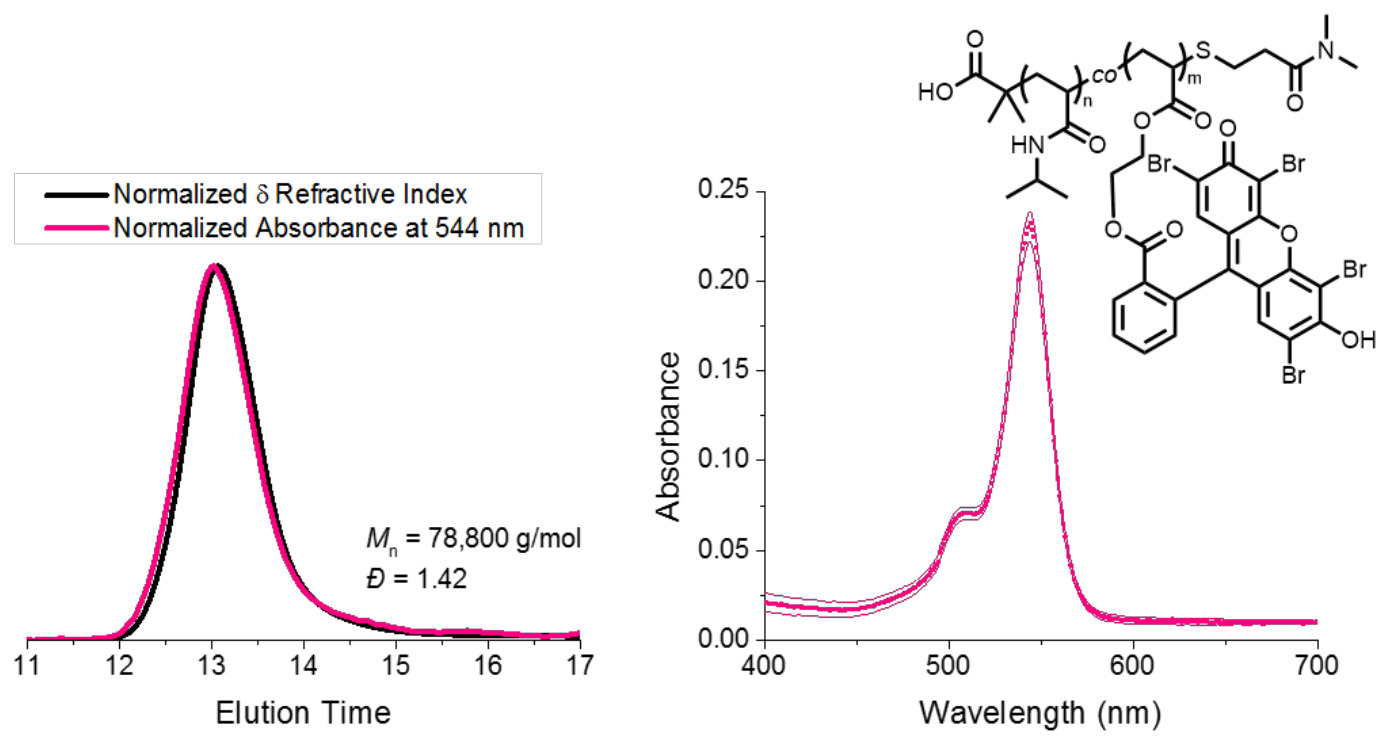

Figure S4: Normalized differential refractive index trace overlaid with the UV-vis trace from SEC indicating the polymeric photocatalyst molecular weight and demonstrating that eosin $Y$ acrylate was incorporated into the polymer (left) and UV-vis absorbance spectra of the photocatalyst (right). The absorbance trace is an average of five measurements; the dots indicate the average absorbance at each wavelength and the lines indicate the error in the measurement.

\section{Eosin Y Methyl Ester (EYMe) UV-vis Absorbance Assay in DMSO}

EYMe $(25.16 \mathrm{mg}, 38.01 \mu \mathrm{mol})$ was dissolved in DMSO $(200 \mathrm{~mL})$ to give a stock solution with a concentration of $190.1 \mu \mathrm{mol} / \mathrm{L}$. The stock solution $(2.0 \mathrm{~mL})$ was diluted with DMSO resulting in a concentration of $19.01 \mu \mathrm{mol} / \mathrm{L}$ (Stock 1). Stock 1 was used to make solutions with concentrations of 14.25, 9.50, 7.13, 4.75, 3.56, 2.38, 1.78, and $1.19 \mu \mathrm{mol} / \mathrm{L}$ through serial dilution. UV-vis spectroscopy (425-625 $\mathrm{nm}$ ) of each concentration (sample volume $=200 \mu \mathrm{L}$ ) was obtained (Figure S5, left). The maximum absorbance for all concentrations below a value of 1.00 were used to develop the concentration assay (Figure S5, right).
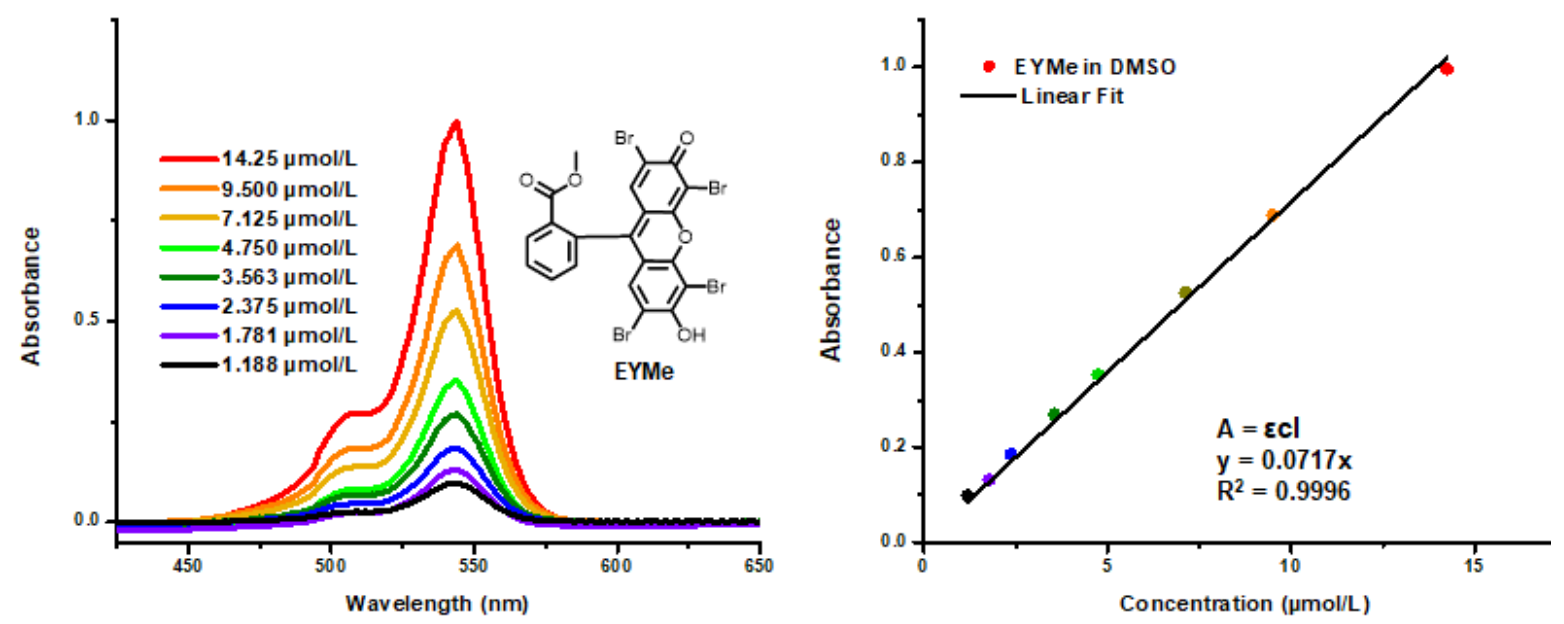

Figure S5: UV-vis absorbance spectra for different concentrations of EYMe from 425-625 nm (left) and maximum absorbance values plotted as a function of concentration (right). 


\section{CTA 1a Synthesis}

Scheme S1: Reaction scheme showing synthesis of 2-(ethylthiocarbonothioy/thio)propanoic acid, 1a.

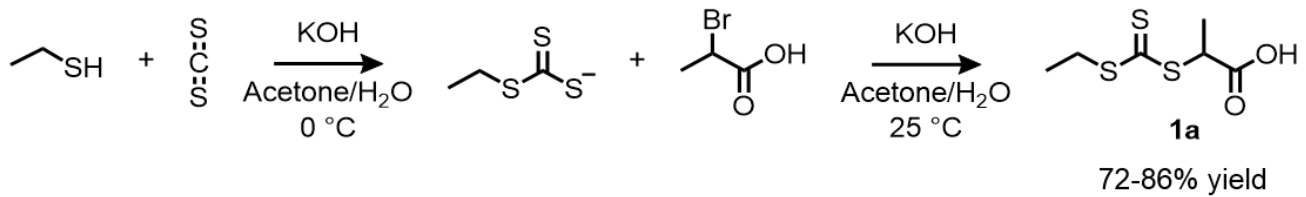

2-(Ethylthiocarbonothioylthio)propanoic acid, 1 a.

The synthesis of 1a was adapted from a procedure by Konkoleweicz et. al. ${ }^{4}$ A solution of potassium hydroxide $\left(20.4 \mathrm{~g}, 0.363 \mathrm{~mol}\right.$ ) in deionized $\mathrm{H}_{2} \mathrm{O}(\mathrm{DI}, 20 \mathrm{~mL}$ ) was added dropwise to a stirred solution of ethanethiol ( $26.2 \mathrm{~mL}, 0.363 \mathrm{~mol})$ and acetone $(400 \mathrm{~mL})$ on ice. After addition, the cloudy solution was stirred for $10 \mathrm{~min}$. Carbon disulfide $(44.0 \mathrm{~mL}, 0.727 \mathrm{~mol})$ was added slowly, yielding a vibrant orange/yellow solution which was stirred on ice for $30 \mathrm{~min}$. The ice bath was removed, and 2-bromo propionic acid ( $50.0 \mathrm{~g}, 0.327 \mathrm{~mol}$ ) was added. The reaction was stirred overnight (>16 h). After completion, the precipitated $\mathrm{KBr}$ salt was removed by filtration and discarded. The yellow acetone solution containing the CTA was concentrated via rotary evaporation, then the residual oil was dissolved in dichloromethane (DCM, $400 \mathrm{~mL})$. The solution was washed with $1 \mathrm{M} \mathrm{HCl}(1 \times 200 \mathrm{~mL}), \mathrm{DI} \mathrm{H} \mathrm{H}_{2}(2 \times 200 \mathrm{~mL})$, and brine $(1$ $\times 200 \mathrm{~mL}$ ). The organic layer was dried with $\mathrm{MgSO}_{4}$, concentrated by rotary evaporation, and recrystallized once from hexanes $(58.8 \mathrm{~g}, 72-86 \%$ yield).

${ }^{1} \mathrm{H} \mathrm{NMR}\left(400 \mathrm{MHz}, \mathrm{CDCl}_{3}\right) \delta: 4.90(\mathrm{q}, 1 \mathrm{H}), 3.40(\mathrm{q}, 2 \mathrm{H}), 1.66(\mathrm{~d}, 3 \mathrm{H}), 1.38(\mathrm{t}, 3 \mathrm{H})$

${ }^{13} \mathrm{C}$ NMR $\left(125 \mathrm{MHz} \mathrm{CDCl}_{3}\right) \delta: 221.63,176.99,47.43,31.70,16.58,12.95$

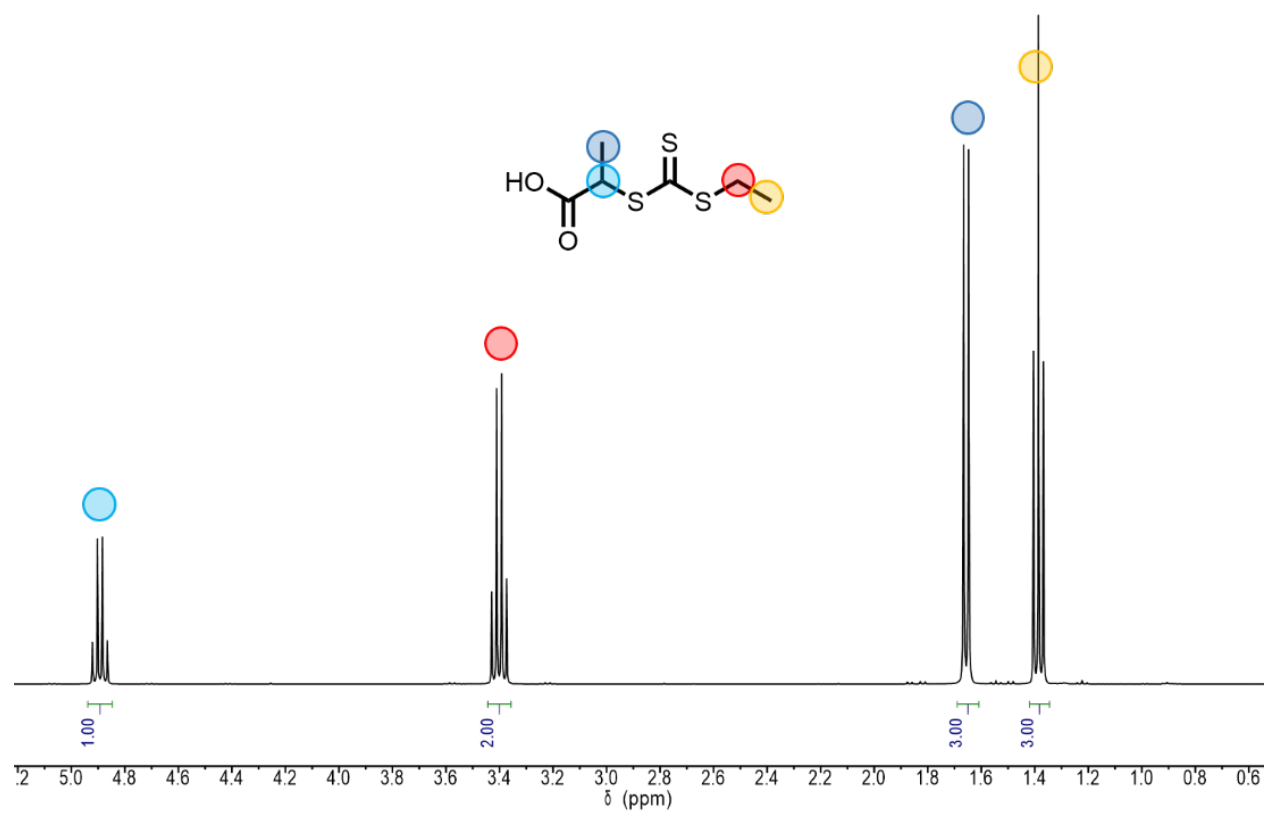

Figure S6: ${ }^{1} \mathrm{H}$ NMR spectrum of 2-(ethylthiocarbonothioylthio)propanoic acid, 1 a. 

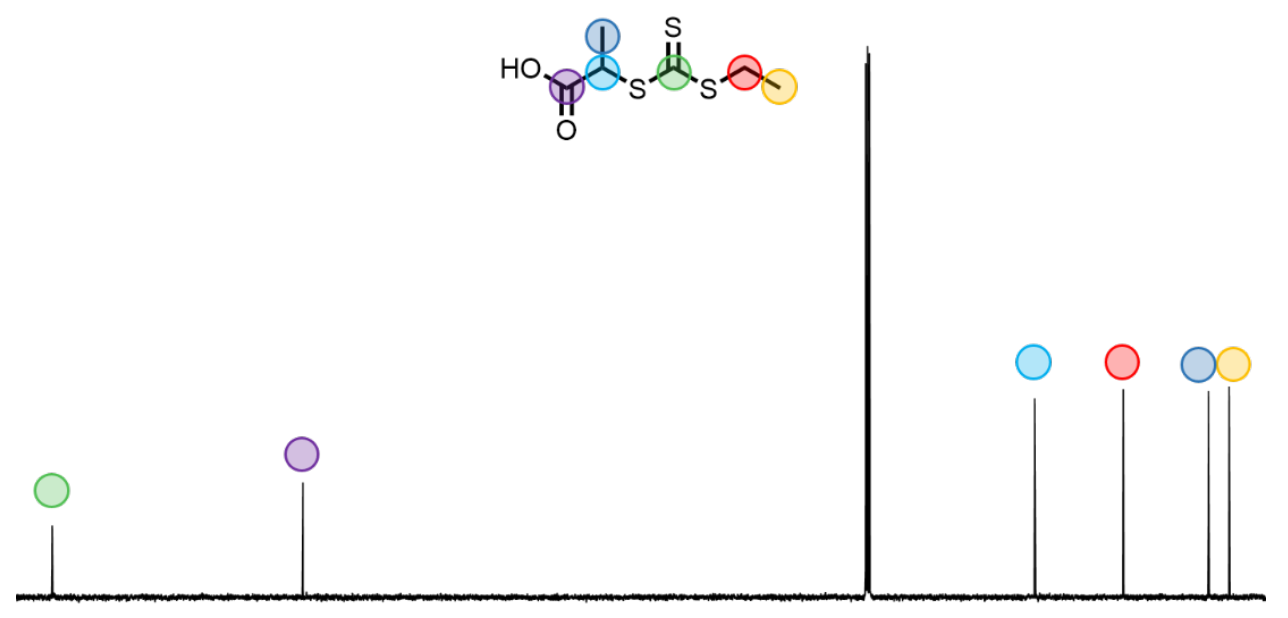

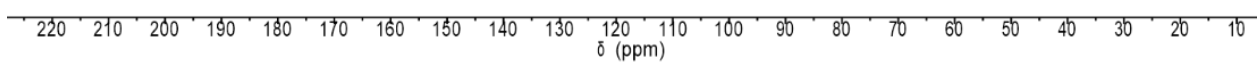

Figure S7: ${ }^{13}$ C NMR spectrum of 2-(ethylthiocarbonothioylthio)propanoic acid, 1 a.

CTA UV-vis absorbance assay

CTA 1a was dissolved in $100 \mathrm{mM} \mathrm{pH} 7.4$ phosphate buffer (PB). The solution was diluted to the concentrations shown in the graph below. All measurements were replicated five times, and the error in the measurements was indicated by error bars. Absorbance assays were used to determine the concentration of species dissolved in solution.
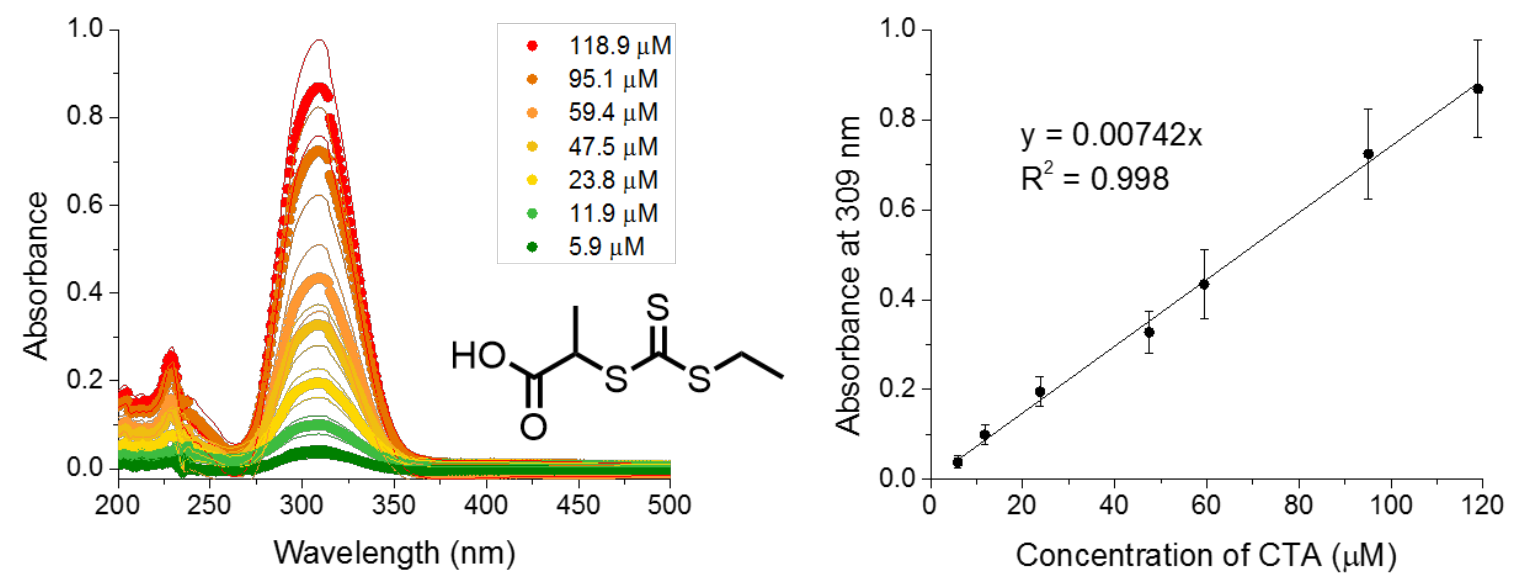

Figure S8: UV-vis absorbance spectra showing CTA 1a at different concentrations (left) and the UV-vis absorbance of CTA 1a at $309 \mathrm{~nm}$ plotted as a function of CTA concentration (right). 


\section{CTA Hydrolysis Studies}

A $2 \mathrm{mg} / \mathrm{mL}$ solution of CTA 1a was made in $\mathrm{pH} 7.4$ water. The CTA 1a solution (10 $\mu \mathrm{L})$ was added to water $(190 \mu \mathrm{L})$ with $\mathrm{pH}=3,7.4$, or 11 (adjusted with $\mathrm{HCl}$ and $\mathrm{NaOH}$ ). The change in $\mathrm{pH}$ from the addition of 10 $\mu \mathrm{L}$ of CTA solution to $190 \mu \mathrm{L}$ was assumed to be negligible. All absorbances were measured in quadruplicate. UV-vis absorbance spectra $(200-500 \mathrm{~nm})$ were measured immediately upon solution formation and $13.5 \mathrm{~h}$ later. Selected spectra at 0 and $13.5 \mathrm{~h}$ for each $\mathrm{pH}$ are overlaid to show there was no appreciable change over time at $\mathrm{pH}=3,7.4$, or 11 . The absorbance at $309 \mathrm{~nm}$ was also monitored continuously over $13.5 \mathrm{~h}$. The average absorbance at $1 \mathrm{~h}$ was normalized to 1 to highlight any differences. These experiments suggested that there was no hydrolysis of the CTA within this time frame at room temperature.
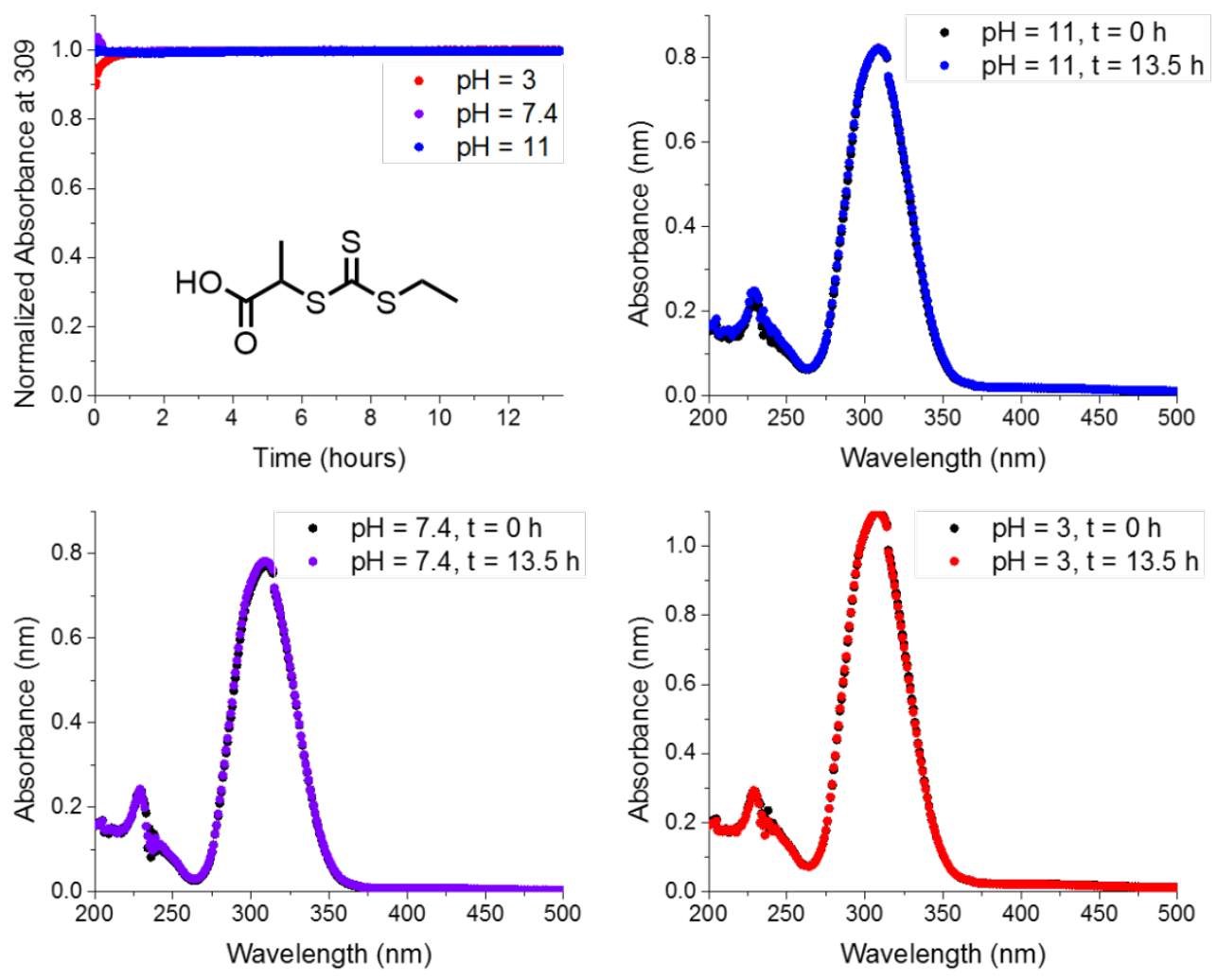

Figure S9: Change in UV-vis absorbance of the CTA 1a over $13 \mathrm{~h}$ at $\mathrm{pH} 3,7.4$, and 11. 


\section{Polymerizations}

\section{Polymerization Method}

Scheme S2: Polymerization of DMA with p(EY-NIPAAm)

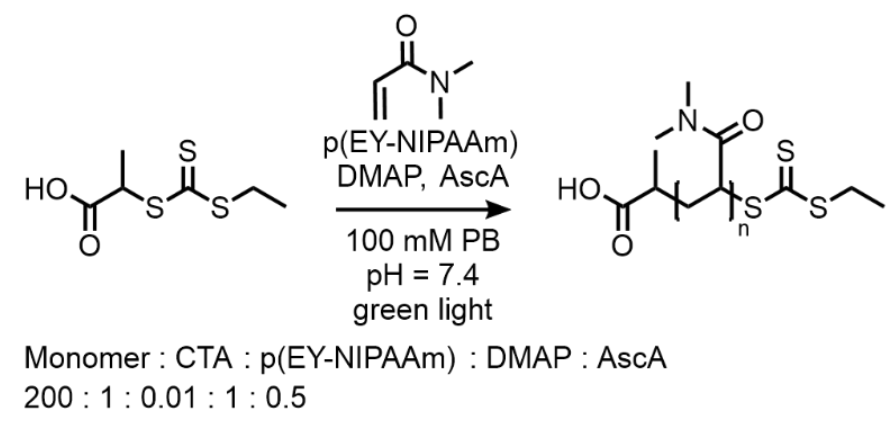

A general polymerization was carried out as follows. Certain variables may have been changed throughout as denoted. P(EY-NIPAAm) $\left(9.3 \mathrm{mg}, 3.0 \times 10^{-5} \mathrm{mmol}\right)$ was combined with $\mathrm{pH}=7.4 \mathrm{~PB}(300 \mu \mathrm{L})$ and the reaction vessel was placed in the refrigerator $\left(10^{\circ} \mathrm{C}\right)$ to solubilize overnight. $\mathrm{P}(\mathrm{EY}-\mathrm{NIPAAm})$ was then combined with CTA 1a (0.63 mg, $0.0030 \mathrm{mmol}, 63 \mu \mathrm{L} 10 \mathrm{mg} / \mathrm{mL}$ PB solution), DMA (62 $\mu \mathrm{L}, 0.60 \mathrm{mmol}$, $0.50 \mathrm{M}$ ), AscA (0.264 mg, $0.00150 \mathrm{mmol}, 26.4 \mu \mathrm{L} 10 \mathrm{mg} / \mathrm{mL}$ PB solution), DMAP $\left(0.367 \mathrm{mg}, 3.00 \times 10^{-3}\right.$ $\mathrm{mmol}, 36.7 \mu \mathrm{L} 10 \mathrm{mg} / \mathrm{mL} \mathrm{PB}$ solution), and $\mathrm{DMF}(50 \mu \mathrm{L})$. $\mathrm{PB}, \mathrm{pH}=7.4$, was added such that the total reaction volume was $1.2 \mathrm{~mL}$.

After combining all components of the reaction, the solution was mixed, and nine aliquots $(120 \mu \mathrm{L})$ were removed and placed in individual, 1.5-mL Eppendorf containers. The samples were placed in a holder and put on the green light. Polymerization was initiated by turning on the light. Two fans and an ice bath were used to limit heating during irradiation and polymerization. Samples were irradiated for $4 \mathrm{~h}$. A single Eppendorf vial was removed every $30 \mathrm{~min}$ and opened to air to quench polymerization. Of the $120 \mu \mathrm{L}$ aliquot, $50 \mu \mathrm{L}$ were combined with $\sim 0.45 \mathrm{~mL}$ of DMSO- $d_{6}$ for ${ }^{1} \mathrm{H}$ NMR analysis, and $35 \mu \mathrm{L}$ were frozen as residual. The final $35 \mu \mathrm{L}$ were combined with PB $(70 \mu \mathrm{L})$, heated in a water bath a $37^{\circ} \mathrm{C}$ for $15-30 \mathrm{~min}$, and filtered through a preheated filter to remove precipitated $p\left(E Y\right.$-NIPAAm). DI water $\left(100 \mu \mathrm{L}, 37^{\circ} \mathrm{C}\right)$ was used to rinse any remaining soluble polymer out of the filter. The filtered samples were frozen in liquid nitrogen and lyophilized prior to addition of $0.5 \mathrm{~mL}$ DMAc. Samples were filtered immediately to limit solvation of residual salts from the PB. Samples sat overnight prior to SEC analysis.

Polymerizations which were degassed with argon (denoted below) where carried out in a $10 \mathrm{~mL}$ Schlenk flask. Aliquots were removed with a degassed syringe. The aliquots were prepared for analysis in the same manner as described above. 


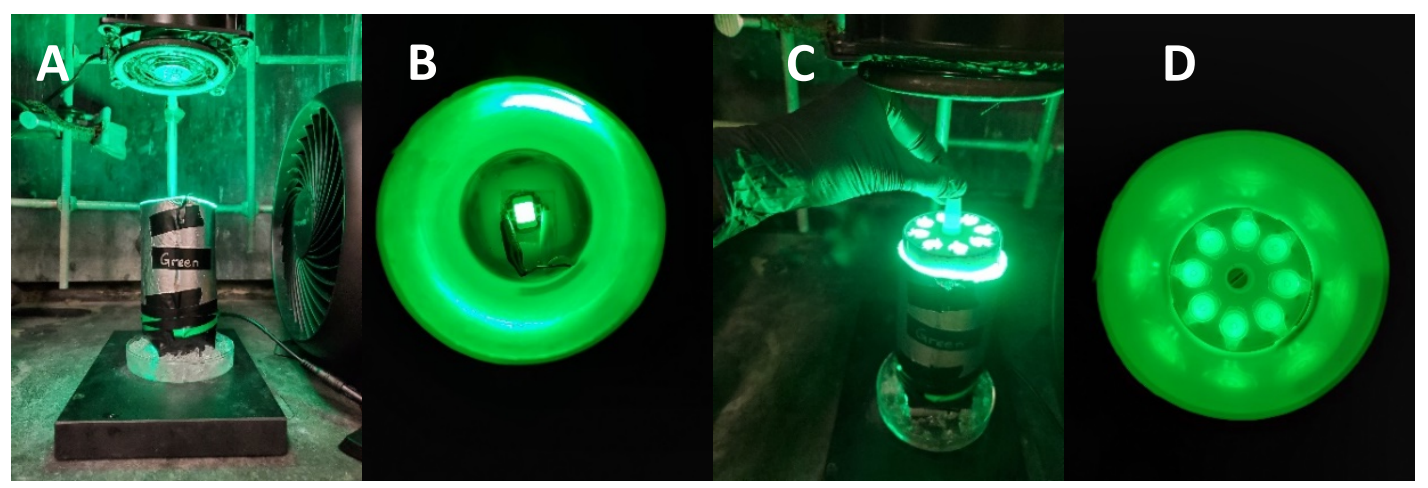

Figure S10: Polymerization setup showing A) the fans around the photoreactor and the ice bath, B) the inside of the photoreactor, $C$ ) the individual reaction aliquots (1.5- $\mathrm{mL}$ Eppendorf containers) in a holder being placed into the photoreactor, and D) a top view into the photoreactor which contains the reaction aliquots (1.5-mL Eppendorfs containers) in their holder.

\section{Polymerization Temperature}

The temperature of the air in the photoreactor was monitored during a DMA polymerization. The experiment was repeated in triplicate and the results are shown below.

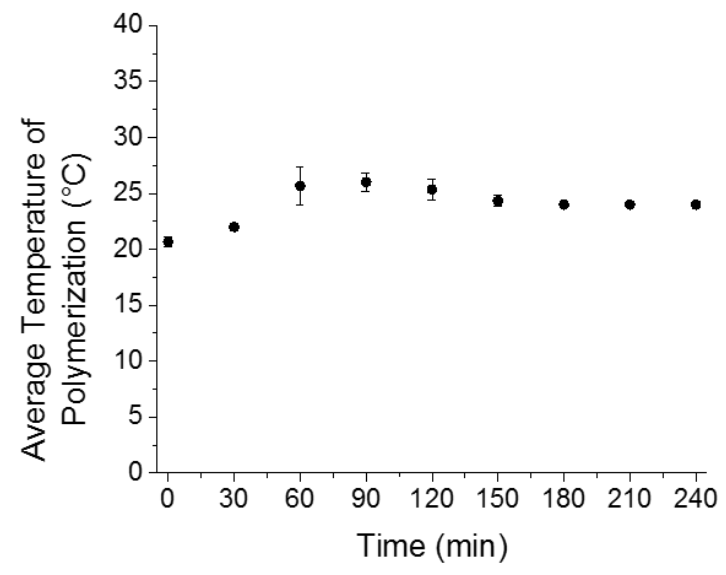

Figure S11: Temperature of the DMA polymerization as a function of time. 
EY UV-Vis Absorbance with DMAP, AscA, and Both

The UV-vis absorbance of a polymerization solution was measured. The polymerization solution contained CTA 1a, (0.63 mg, $0.0030 \mathrm{mmol}, 63 \mu \mathrm{L} 10 \mathrm{mg} / \mathrm{mL}$ PB solution), DMA ( $62 \mu \mathrm{L}, 0.60 \mathrm{mmol}, 0.5 \mathrm{M})$, EY (0.02 $\mathrm{mg}, 3 \times 10^{-5} \mathrm{mmol}, 2 \mu \mathrm{L} 10 \mathrm{mg} / \mathrm{mL}$ DMSO solution), and DMF (50 $\left.\mu \mathrm{L}\right)$. In some cases, the solution also contained AscA ( $0.106 \mathrm{mg}, 6.02 \times 10^{-4} \mathrm{mmol}, 10.6 \mu \mathrm{L}$ of a $10 \mathrm{mg} / \mathrm{mL}$ PB solution), DMAP $(0.367 \mathrm{mg}, 3.00$ $\times 10^{-3} \mathrm{mmol}, 36.7 \mu \mathrm{L}$ of a $10 \mathrm{mg} / \mathrm{mL}$ PB solution), or both, as indicated in the graph below. The total reaction volume was $1.2 \mathrm{~mL}$ in $\mathrm{pH}=7.4 \mathrm{~PB}$.

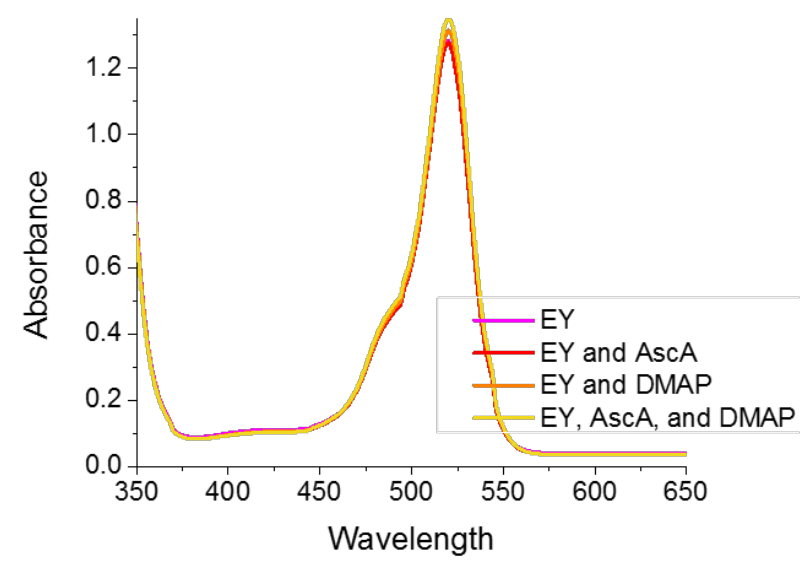

Figure S12: UV-vis absorbance spectra of the polymerization containing EY and other components as denoted.

EY UV-vis Absorbance vs. pH

EY was dissolved in DMSO to make a $1 \mathrm{mg} / \mathrm{mL}$ solution, which was diluted to $0.1 \mathrm{mg} / \mathrm{mL}$. The EY solution $(10 \mu \mathrm{L})$ was added to water $(190 \mu \mathrm{L})$ with $\mathrm{pH} 3-11$, adjusted with $\mathrm{HCl}$ and/or $\mathrm{NaOH}$. The average UV-vis absorbance spectra of three trials for each $\mathrm{pH}$ are shown. The average absorbance of the solution in $\mathrm{pH}$ 7.4 $\mathrm{PB}$ is also shown.

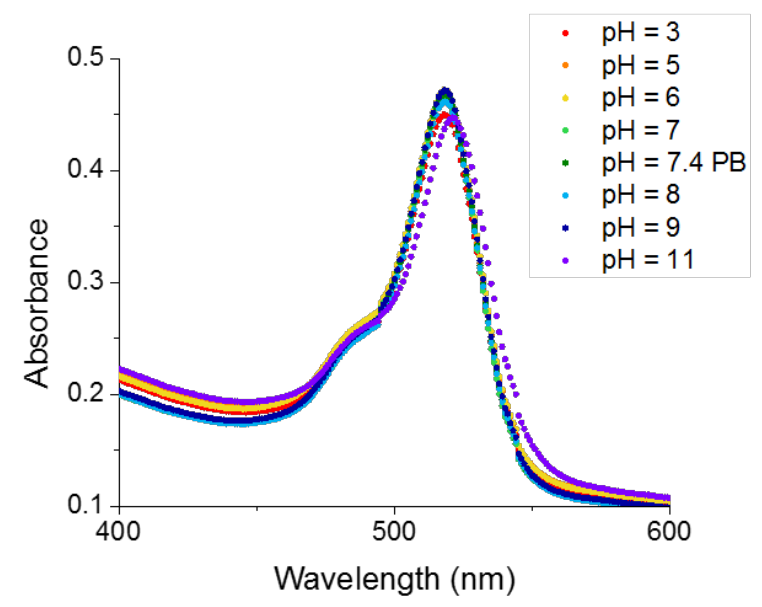

Figure S13: UV-vis average absorbance spectra of EY at pH values between 3 and 11. 


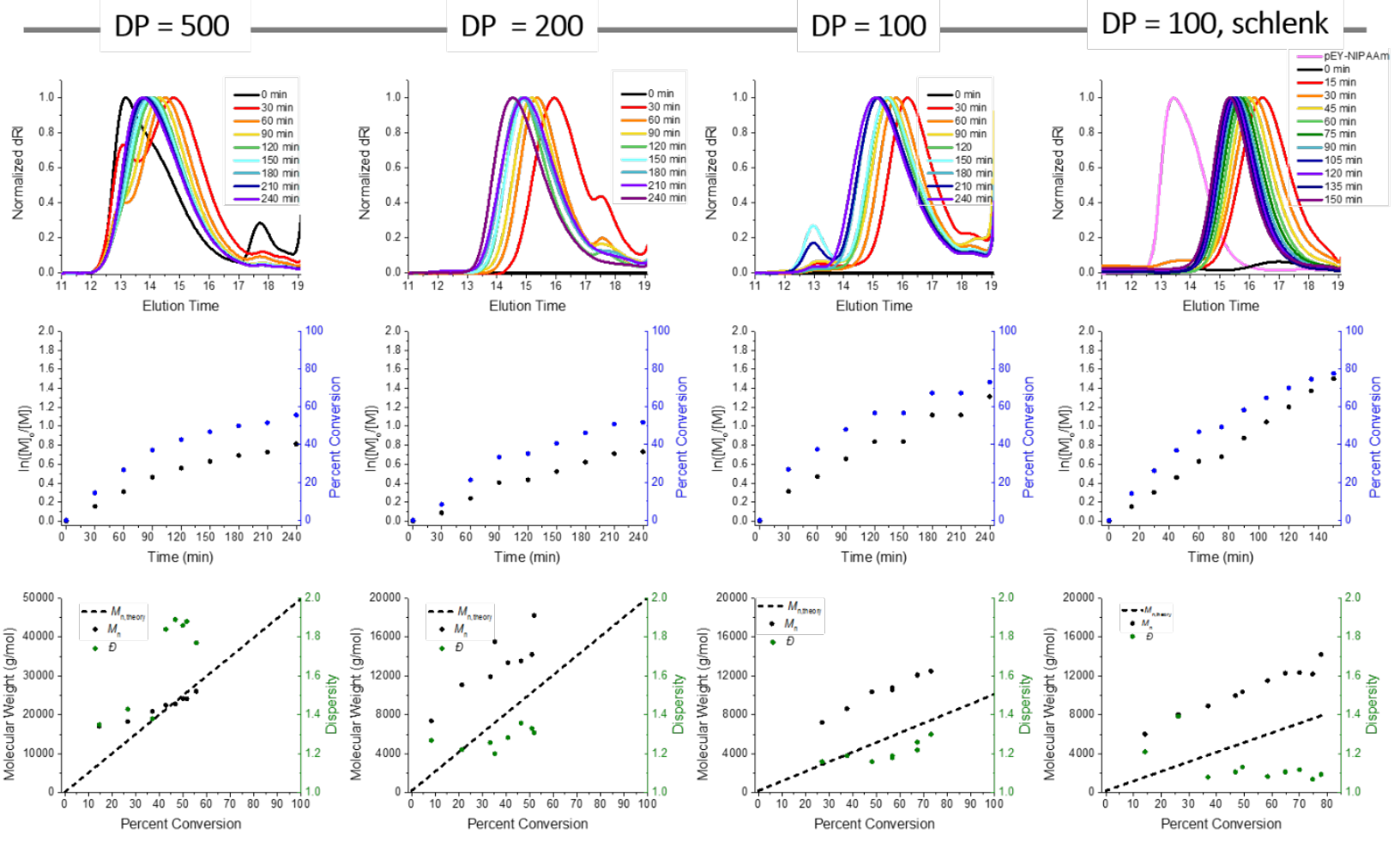

Figure S14: MW and kinetic data for DMA polymerizations targeting different degrees of polymerization. See Table S1 for reaction conditions. The degree of polymerization was varied. Two equivalents of ascorbic acid were used for these polymerizations; all other conditions were identical to those described in the "Polymerization Method" section. The polymerization conducted under argon was carried out in a 10-mL Schlenk flask.

Table S1: Reactions targeting different degrees of polymerization for DMA.

\begin{tabular}{|c|c|c|c|c|c|c|}
\hline $\begin{array}{l}\text { [Monomer] : [CTA] : } \\
{[\text { (E)-NIPAAm)] : }} \\
{[\text { DMAP] : [AscA] }}\end{array}$ & $\begin{array}{l}\text { Degas } \\
\text { Method }\end{array}$ & $\begin{array}{l}\text { Time } \\
\text { (h) }\end{array}$ & Light & $\begin{array}{l}\text { Conversion } \\
\text { (\%) }\end{array}$ & $M_{\text {nGPC: }}: M_{\text {ntheory }}$ & $\boldsymbol{\theta}$ \\
\hline 500:1:0.01:1:2 & AscA & 4 & Green & 56 & $26,100: 27,800$ & 1.77 \\
\hline 200:1:0.01:1:2 & AscA & 4 & Green & 52 & $18,200: 9,100$ & 1.33 \\
\hline 100:1:0.01:1:2 & AscA & 4 & Green & 73 & $12,500: 7,400$ & 1.30 \\
\hline 100:1:0.01:1:0 & Argon & 2.5 & Green & 78 & $14,200: 11,800$ & 1.09 \\
\hline
\end{tabular}

All polymerizations were carried out under green light at a monomer concentration of $0.5 \mathrm{M}$ with $\mathrm{p}$ (EYNIPAAm) photocatalyst. MW and kinetic data are shown above (Figure S14). The degree of polymerization was varied. Two equivalents of ascorbic acid were used for these polymerizations; all other conditions were identical to those described in the "Polymerization Method" section. The polymerization conducted under argon was carried out in a 10-mL Schlenk flask. 
Effect of Ascorbic Acid Concentration

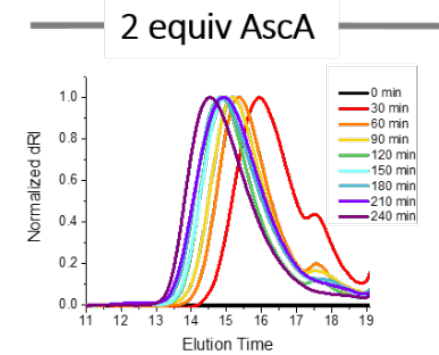

1 equiv AscA

0.5 equiv AscA
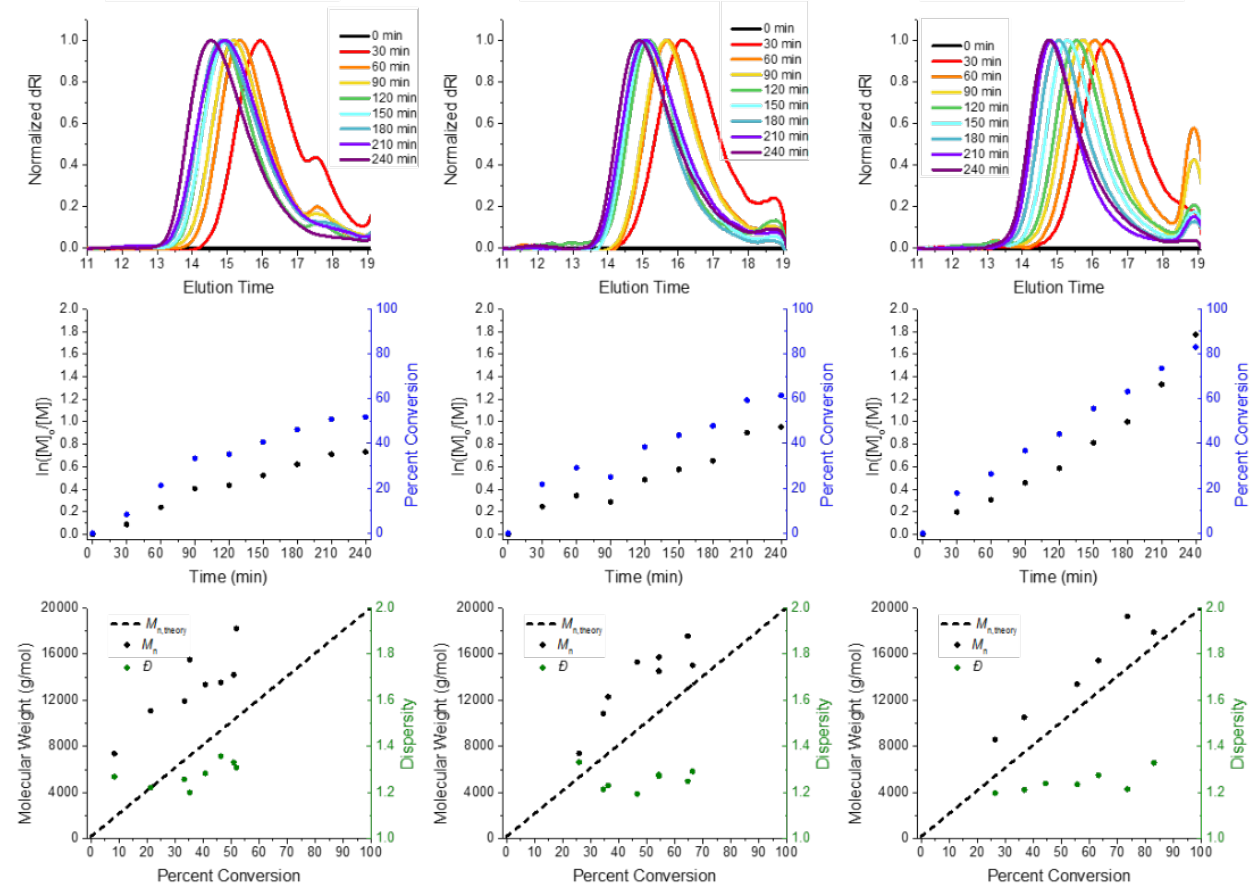

0.3 equiv AscA

0.1 equiv AscA
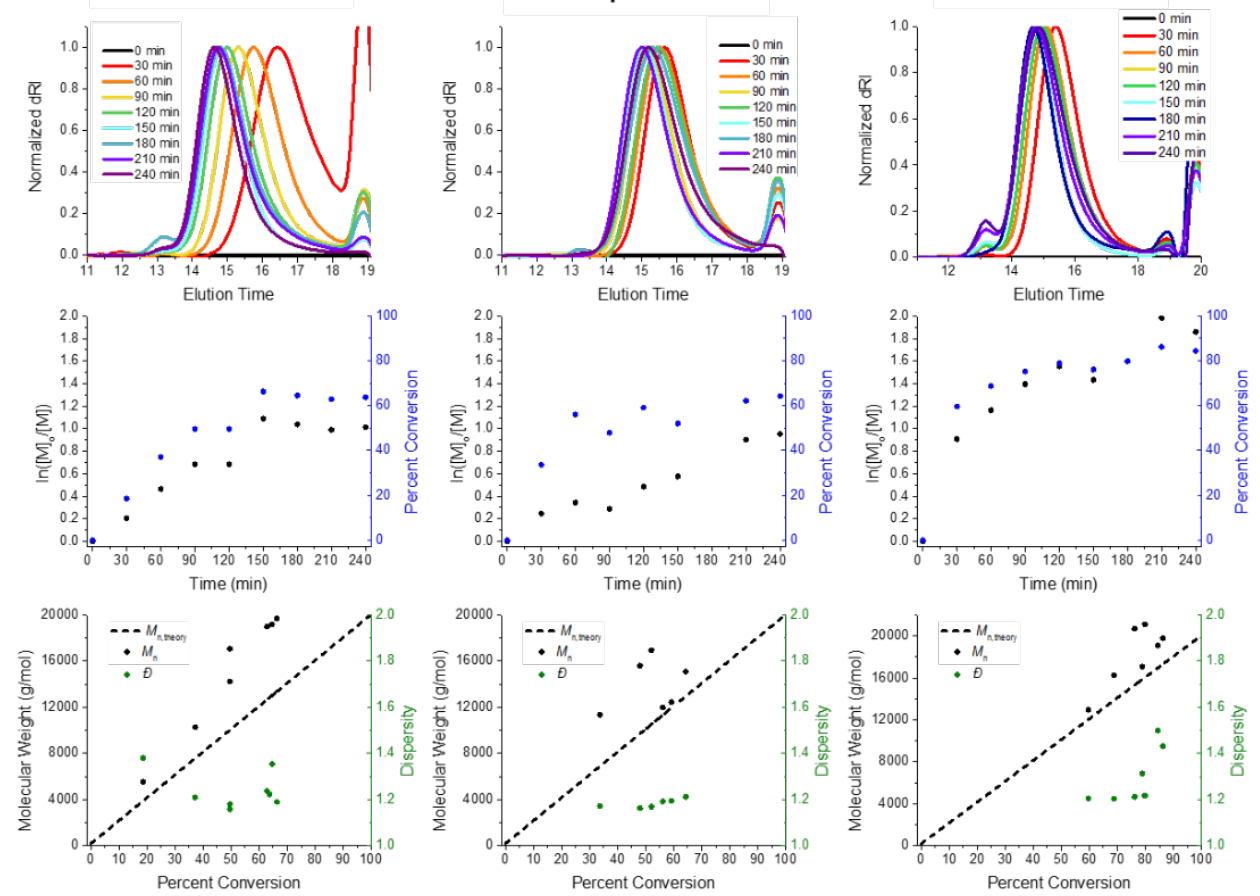

Figure S15: MW and kinetic data for DMA polymerizations containing different concentrations of AscA without degassing. See Table S2 for reaction conditions. The ascorbic acid concentration was varied; all other conditions were identical to those described in the "Polymerization Method" section. 
Table S2: DMA polymerizations containing different concentrations of AscA without degassing.

\begin{tabular}{|c|c|c|c|c|c|c|}
\hline $\begin{array}{l}\text { [Monomer] : [CTA] : } \\
\text { [p(EY-NIPAAm)] : } \\
{[\text { DMAP] : [AscA] }}\end{array}$ & $\begin{array}{l}\text { Degas } \\
\text { Method }\end{array}$ & $\begin{array}{l}\text { Time } \\
\text { (h) }\end{array}$ & Light & $\begin{array}{l}\text { Conversion } \\
\text { (\%) }\end{array}$ & $M_{\text {nGPC: }}: M_{\text {ntheory }}$ & $\boldsymbol{\theta}$ \\
\hline 200:1:0.01:1:2 & AscA & 4 & Green & 52 & $18,100: 10,500$ & 1.34 \\
\hline 200:1:0.01:1:1 & AscA & 4 & Green & 61 & $17,600: 12,400$ & 1.25 \\
\hline 200:1:0.01:1:0.5 & AscA & 4 & Green & 83 & $18,400: 16,700$ & 1.30 \\
\hline 200:1:0.01:1:0.3 & AscA & 4 & Green & 91 & $21,900: 18,300$ & 1.22 \\
\hline 200:1:0.01:1:0.1 & AscA & 4 & Green & 75 & $14,000: 15,100$ & 1.28 \\
\hline 200:1:0.01:1:0 & - & 4 & Green & 85 & $19,700: 17,200$ & 1.55 \\
\hline
\end{tabular}

All polymerizations were carried out under green light at a monomer concentration of $0.5 \mathrm{M}$ with $\mathrm{p}$ (EYNIPAAm) photocatalyst. MW and kinetic data are shown above (Figure S15). The ascorbic acid concentration was varied; all other conditions were identical to those described in the "Polymerization Method" section.

Table S3: DMA polymerizations containing different concentrations of AscA carried out in oxygen free conditions.

\begin{tabular}{lllllll}
\hline $\begin{array}{l}\text { [Monomer] : [CTA] : } \\
\text { [p(EY-NIPAAm)] : }\end{array}$ & $\begin{array}{l}\text { Degas } \\
\text { Method }\end{array}$ & $\begin{array}{l}\text { Time } \\
\text { [D) }\end{array}$ & Light & $\begin{array}{l}\text { Conversion } \\
(\%)\end{array}$ & $\boldsymbol{M}_{\text {nGPC: }} \boldsymbol{M}_{\text {ntheory }}$ & च \\
\hline 200:1:0.01:1:2 & Argon & 4 & Green 77 & $21,700: 15,500$ & 1.42 \\
\hline 200:1:0.01:1:1 & Argon & 4 & Green 82 & $20,400: 16,500$ & 1.36 \\
\hline 200:1:0.01:1:0.5 & Argon & 4 & Green 91 & $22,200: 18,300$ & 1.27 \\
\hline 200:1:0.01:1:0.3 & Argon & 4 & Green 93 & $14,400: 18,700$ & 1.26 \\
\hline 200:1:0.01:1:0.1 & Argon & 4 & Green 96 & $21,600: 19,300$ & 1.19 \\
\hline 200:1:0.01:1:0 & Argon & 4 & Green 88 & $18,960: 17,800$ & 1.16 \\
\hline All
\end{tabular}

All polymerizations were carried out under green light at a monomer concentration of $0.5 \mathrm{M}$ with $\mathrm{p}$ (EYNIPAAm) photocatalyst. The ascorbic acid concentration was varied; all other conditions were identical to those described in the "Polymerization Method" section. The polymerizations conducted under argon were carried out in a $10-\mathrm{mL}$ Schlenk flask. 

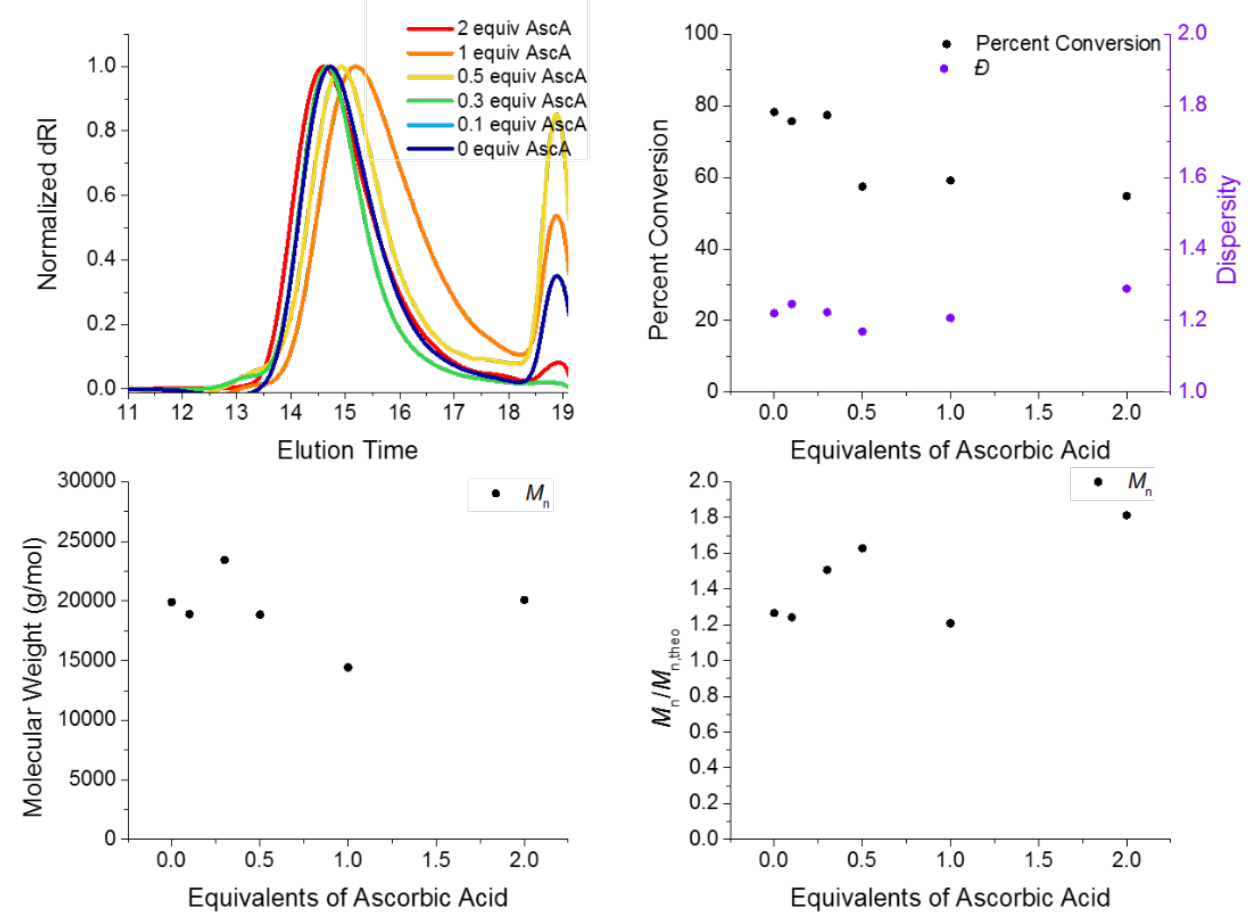

Figure S16: $M W$ and kinetic data for DMA polymerizations containing different concentrations of AscA without degassing and without DMAP. See Table S4 for reaction conditions. DMAP was omitted, and the ascorbic acid concentration was varied; all other conditions were identical to those described in the "Polymerization Method" section.

Table S4: DMA polymerizations containing different concentrations of AscA without degassing and without DMAP.

\begin{tabular}{|c|c|c|c|c|c|c|}
\hline $\begin{array}{l}\text { [Monomer] : [CTA] : } \\
{[\text { (E) EY-NIPAAm)] : }} \\
{[\text { DMAP] : [AscA] }}\end{array}$ & $\begin{array}{l}\text { Degas } \\
\text { Method }\end{array}$ & $\begin{array}{l}\text { Time } \\
\text { (h) }\end{array}$ & Light & $\begin{array}{l}\text { Conversion } \\
\text { (\%) }\end{array}$ & $M_{\text {nGPC: }}: M_{\text {ntheory }}$ & $\boldsymbol{\oplus}$ \\
\hline 200:1:0.01:0:2 & AscA & 4 & Green & 55 & $20,100: 11,100$ & 1.29 \\
\hline 200:1:0.01:0:1 & AscA & 4 & Green & 59 & $14,400: 11,900$ & 1.21 \\
\hline 200:1:0.01:0:0.5 & AscA & 4 & Green & 57 & $18,900: 11,600$ & 1.17 \\
\hline 200:1:0.01:0:0.3 & AscA & 4 & Green & 77 & $23,400: 15,500$ & 1.22 \\
\hline 200:1:0.01:0:0.1 & AscA & 4 & Green & 76 & $18,900: 15,200$ & 1.25 \\
\hline 200:1:0.01:0:0 & - & 4 & Green & 78 & $19,900: 15,700$ & 1.22 \\
\hline
\end{tabular}

All polymerizations were carried out under green light at a monomer concentration of $0.5 \mathrm{M}$ with $\mathrm{p}$ (EYNIPAAm) photocatalyst. MW and kinetic data are shown above (Figure S16). DMAP was omitted and the ascorbic acid concentration was varied; all other conditions were identical to those described in the "Polymerization Method" section. 
Comparison of Different Wavelengths of Light
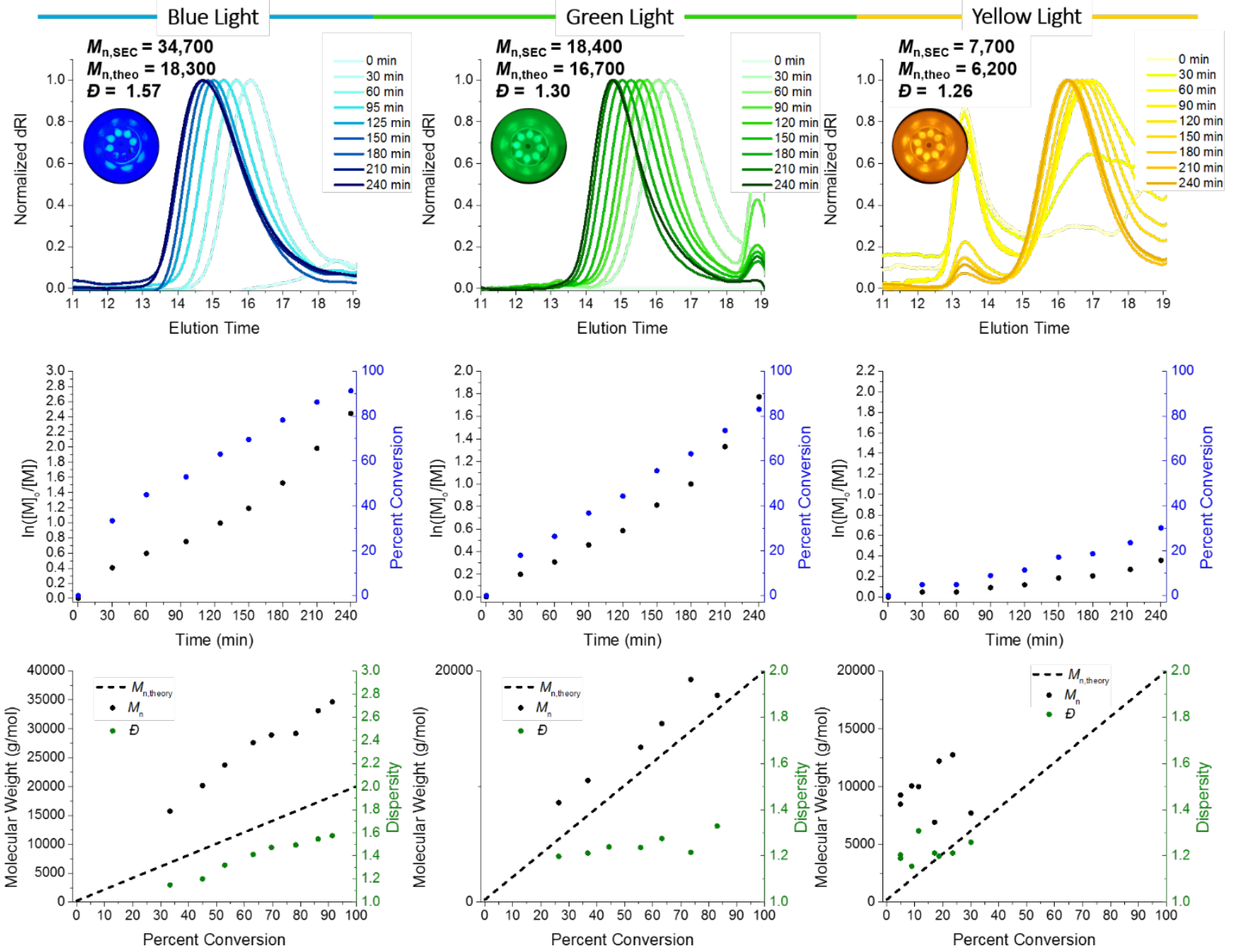

Figure S17: MW and kinetic data for DMA polymerizations carried out under different wavelengths and intensities of light. See Table S5 for reaction conditions. The light source was varied; all other conditions were identical to those described in the "Polymerization Method" section.

Table S5: DMA polymerizations carried out under different wavelengths and intensities of light.

\begin{tabular}{lllllll}
$\begin{array}{l}\text { [Monomer] : [CTA] : } \\
\text { [p(EY-NIPAAm)] : } \\
\text { [DMAP] : [AscA] }\end{array}$ & $\begin{array}{l}\text { Degas } \\
\text { Method }\end{array}$ & $\begin{array}{l}\text { Time } \\
(\mathrm{h})\end{array}$ & Light & $\begin{array}{l}\text { Conversion } \\
(\%)\end{array}$ & $\boldsymbol{M}_{\text {nGPC: }} \boldsymbol{M}_{\text {ntheory }}$ & $\boldsymbol{Ð}$ \\
\hline 200:1:0.01:1:0.5 & AscA & 4 & Blue & 91 & $34,700: 18,300$ & 1.57 \\
\hline 200:1:0.01:1:0.5 & AscA & 4 & Green & 83 & $18,400: 16,700$ & 1.30 \\
\hline 200:1:0.01:1:0.5 & AscA & 4 & Yellow 30 & $7,700: 6,200$ & 1.26 \\
\hline
\end{tabular}

All polymerizations were carried out at a monomer concentration of $0.5 \mathrm{M}$ with the $\mathrm{p}$ (EY-NIPAAm) photocatalyst. MW and kinetic data are shown above (Figure S17). The polymerization performed with yellow light was conducted at twice the typical reaction volume and double the amount of polymer was used to prepare each SEC sample. The wavelength and intensity of light were varied; other conditions were described in the "Polymerization Method" section. 


\section{UV-vis Absorbance of $\mathrm{p}$ (EY-NIPAAm) compared to EY in Polymerization Solution}

The UV-vis absorbance of a polymerization solution was measured with EY and with the p(EY-NIPAAm) photocatalyst. The polymerization solution was prepared as denoted in the polymerization methods section with a [DMA] : [CTA] : [p(EY-NIPAAm)] or [EY] : [DMAP] : [AscA] of 200:1:0.01:1:0.5. The solution contained either EY $\left(0.02 \mathrm{mg}, 3 \times 10^{-5} \mathrm{mmol}, 2 \mu \mathrm{L} 10 \mathrm{mg} / \mathrm{mL}\right.$ DMSO solution) or p(EY-NIPAAm) $(9.3 \mathrm{mg}$, $3.0 \times 10^{-5} \mathrm{mmol}$ ). The total reaction volume was $1.2 \mathrm{~mL}$ in $100 \mathrm{mM} \mathrm{pH}=7.4 \mathrm{~PB}$.

The UV-vis absorbance of $p(E Y-N I P A A m)\left(\lambda_{\max }=534 \mathrm{~nm}\right)$ was red-shifted $14 \mathrm{~nm}$ compared to EY $\left(\lambda_{\max }=520\right.$ $\mathrm{nm}$ ) in the polymerization solution.

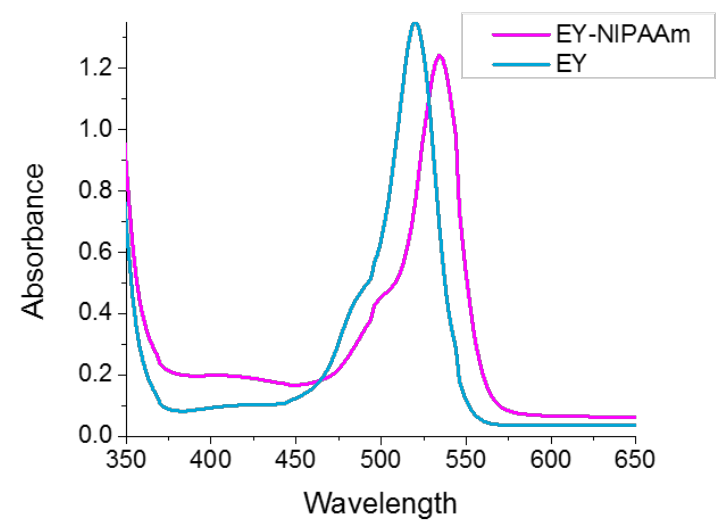

Figure S18: UV-vis absorbance spectra of EY and $p(E Y-N I P A A m)$ in the polymerization solution. The solution had a [DMA] : [CTA] : [p(EY-NIPAAm)] or [EY] : [DMAP] : [AsCA] of 200:1:0.01:1:0.5.

\section{Polymerization UV-vis Absorbance}

The UV-vis absorbance of a polymerization solution irradiated with green light was measured over time. The polymerization solution was prepared as described in the "Polymerization Methods" section. The polymerization solution was placed in a cuvette and irradiated with green light in 30 min increments for a total of $240 \mathrm{~min}$. Every $30 \mathrm{~min}$, the cuvette was removed from the photoreactor, and the UV-vis absorbance was measured. The photoreactor was kept cool with two fans and an ice bath.

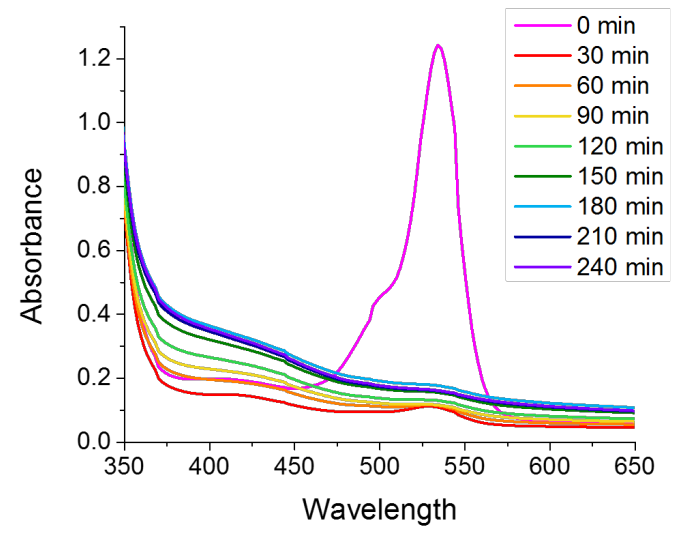

Figure S19: UV-vis absorbance spectra of DMA polymerization with $p(E Y$-NIPAAm) over $4 \mathrm{~h}$ of green light irradiation. The solution had a [DMA] : [CTA] : [p(EY-NIPAAm)] : [DMAP] : [AscA] of 200:1:0.01:1:0.5. 
Photomediation of DMA Polymerizations
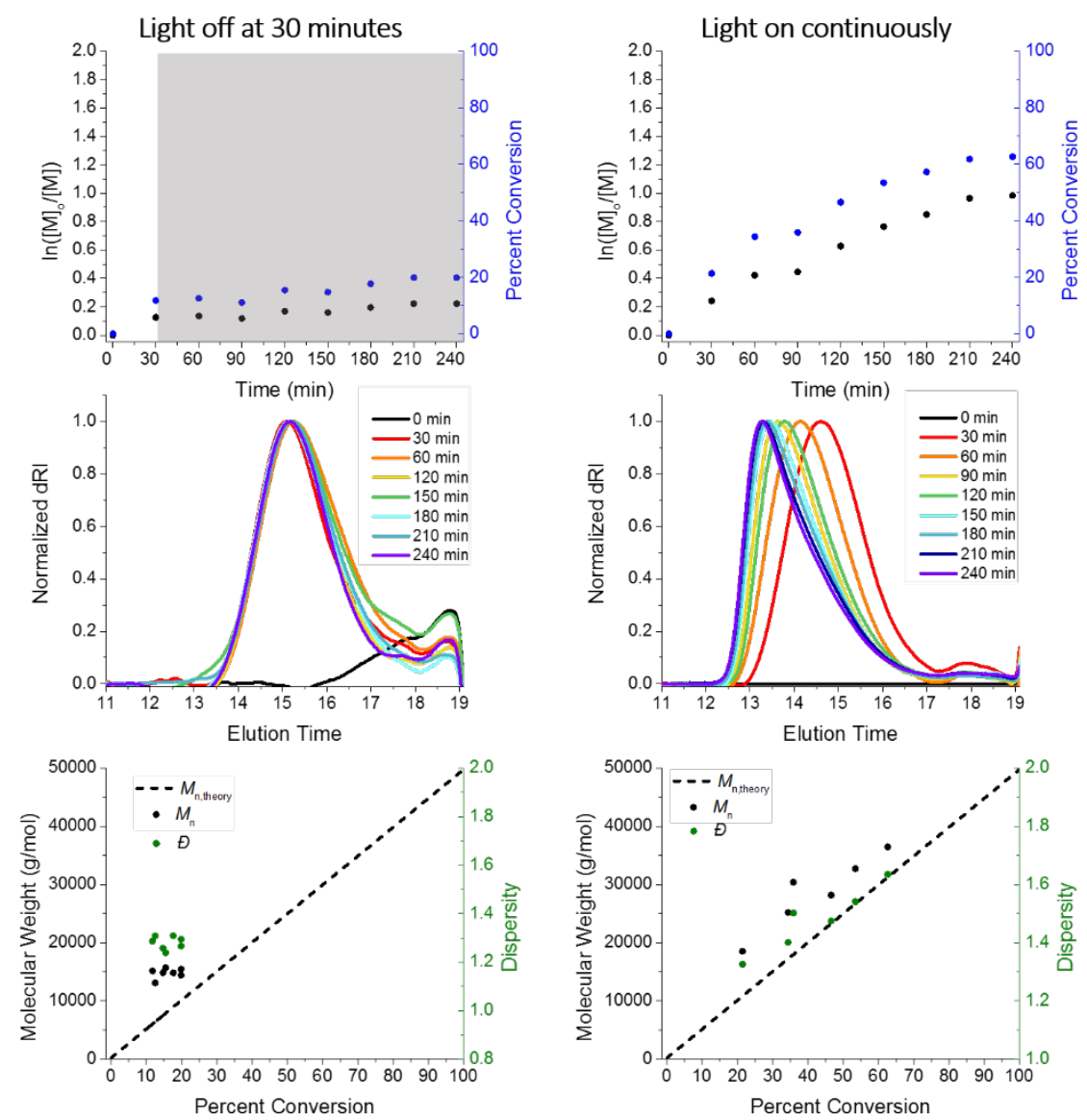

Figure S20: $M W$ and kinetic data for DMA polymerization showing that there was very little conversion after the light was turned off. Photomediation was occurring with $p(E Y-N I P A A m)$ throughout the polymerization when the light was on. [DMA] : [CTA] : [p(EY-NIPAAm)] : [DMAP] : [AsCA] ratio was 500:1:0.1:1:2. All other conditions were identical to those described in the "Polymerization Method" section. 
Polymerization of 4-Acryloylmorpholine (NMO)

Scheme S3: Polymerization of NMO with p(EY-NIPAAm)

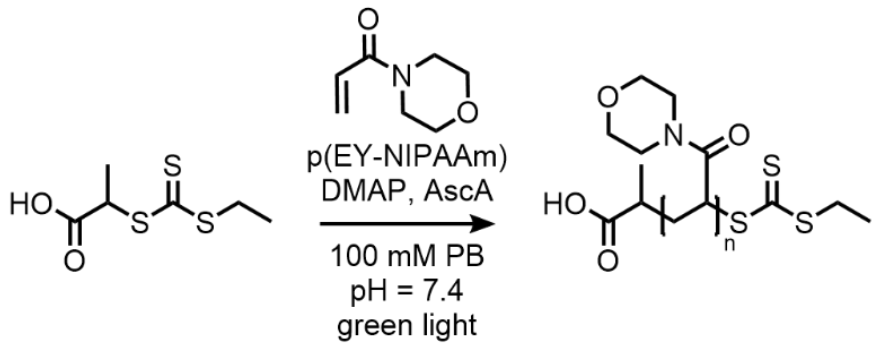

Monomer : CTA : p(EY-NIPAAm) : DMAP : AscA

$200: 1: 0.01: 1: 0.5$
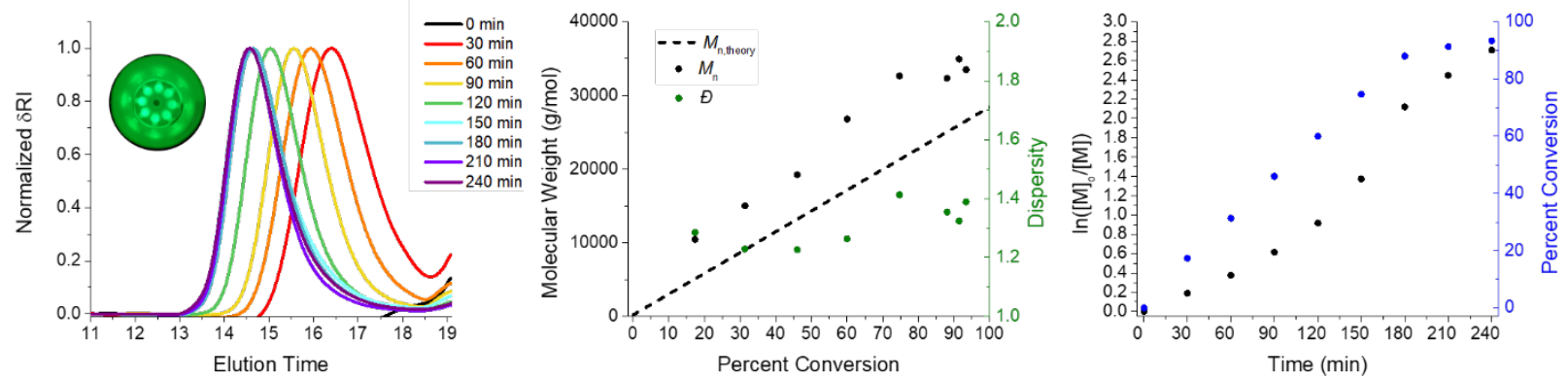

Figure S21: MW and kinetic data for the polymerization of NMO. The [NMO] : [CTA] : [p(EY-NIPAAm)] : [DMAP] : [AscA] ratio was 200:1:0.1:1:0.5. All other conditions were identical to those described in the "Polymerization Method" section.

\section{Photocatalyst Recycling}

Polymerization one:

A polymerization solution was prepared as described in the "Polymerization Methods" section above. Each polymerization was run in a single 1.5-mL Eppendorf container. This reaction was run in triplicate.

An initial timepoint $(120 \mu \mathrm{L})$ was removed from the reaction solution prior to polymerization. Polymerizations were initiated by turning on the green light. Two fans and an ice bath were used to limit heating. Samples were irradiated for $3.5 \mathrm{~h}$. After polymerization, the reaction mixture was heated to $37^{\circ} \mathrm{C}$ in a water bath for $15 \mathrm{~min}$. The precipitated p(EY-NIPAAm) photocatalyst was removed by centrifuging the sample at $10,000 \mathrm{rpm}$ for $3 \mathrm{~min}$ at $25^{\circ} \mathrm{C}$. The polymerization solution was decanted, and samples were removed for analysis by ${ }^{1} \mathrm{H}$ NMR and SEC. SEC traces show that removal of the photocatalyst via this method was efficient.

The centrifuged $p(E Y-N I P A A m)$ pellet was combined with room temperature PB $(1 \mathrm{~mL})$ and vortexed, and the heating and centrifugation cycle was repeated. Decanting, dilution, and centrifugation with DI water were repeated a final time to attempt to removal any residual reaction components or salt from the PB. The catalyst solution was frozen, and the water was removed via lyophilization. The recovered yield of the photocatalyst was $9.3 \mathrm{mg} \pm 0.8 \mathrm{mg}$ with a theoretical yield of $8.4 \mathrm{mg}$, or $110 \% \pm 9 \%$. The recovery yield was greater than 100 percent, indicating that some residual reaction components remained (buffer components). 


\section{Polymerization two:}

Polymerization two was carried out assuming that 100 percent of the theoretical maximum amount of $\mathrm{p}$ (EY-NIPAAm) photocatalyst was recovered from polymerization one, taking into consideration the amount removed for any aliquots. The molar ratio of reactants remained the same, but the amount of each reactant was adjusted.

$\mathrm{P}$ (EY-NIPAAm) recovered from polymerization one $\left(8.4 \mathrm{mg}, 2.7 \times 10^{-5} \mathrm{mmol}\right)$ was combined with $\mathrm{pH}=7.4$ PB $(300 \mu \mathrm{L})$ and put in the refrigerator $\left(10^{\circ} \mathrm{C}\right)$ to solubilize overnight. The polymeric photocatalyst was then combined with CTA 1a $(0.572 \mathrm{mg}, 0.00272 \mathrm{mmol}, 57.2 \mu \mathrm{L}$ of a $10 \mathrm{mg} / \mathrm{mL}$ PB solution), DMA ( $56 \mu \mathrm{L}$, $0.54 \mathrm{mmol}, 0.5 \mathrm{M}$ ), AscA (0.239 mg, $0.00136 \mathrm{mmol}, 23.9 \mu \mathrm{L}$ of a $10 \mathrm{mg} / \mathrm{mL}$ PB solution), DMAP (0.332 mg, $2.72 \times 10^{-3} \mathrm{mmol}, 33.2 \mu \mathrm{L}$ of a $10 \mathrm{mg} / \mathrm{mL}$ PB solution), and DMF $(50 \mu \mathrm{L}) . \mathrm{PB}, \mathrm{pH}=7.4$, was added such that the total reaction volume was $1.088 \mathrm{~mL}$. This reaction was run in triplicate.

An initial timepoint $(100 \mu \mathrm{L})$ was removed from the reaction solution prior to polymerization. Polymerizations were run, processed, and analyzed as stated in polymerization one. The recovered yield of the photocatalyst was $10.1 \mathrm{mg} \pm 0.9 \mathrm{mg}$ compared to a theoretical yield of $7.6 \mathrm{mg}$, or $133 \% \pm 11 \%-$ suggesting residual buffer components were present.

\section{Polymerization three:}

Polymerization three was carried out assuming that 100 percent of the theoretical maximum amount of p(EY-NIPAAm) photocatalyst was recovered, taking into consideration the amount removed for the initial aliquot. The molar ratio of reactants remained the same.

$\mathrm{P}$ (EY-NIPAAm) $\left(7.6 \mathrm{mg}, 2.5 \times 10^{-5} \mathrm{mmol}\right)$ recovered from polymerization two was combined with $\mathrm{pH}=7.4$ PB $(300 \mu \mathrm{L})$ and put in the refrigerator $\left(10^{\circ} \mathrm{C}\right)$ to solubilize overnight. The polymeric photocatalyst was then combined with CTA $1 \mathrm{a}(0.517 \mathrm{mg}, 0.00246 \mathrm{mmol}, 51.7 \mu \mathrm{L}$ of a $10 \mathrm{mg} / \mathrm{mL}$ PB solution), DMA (51 $\mu \mathrm{L}$, $0.49 \mathrm{mmol}, 0.5 \mathrm{M})$, AscA (0.217 mg, $0.00123 \mathrm{mmol}, 21.7 \mu \mathrm{L}$ of a $10 \mathrm{mg} / \mathrm{mL}$ PB solution), DMAP (0.300 mg, $2.46 \times 10^{-3} \mathrm{mmol}, 30.0 \mu \mathrm{L}$ of a $10 \mathrm{mg} / \mathrm{mL}$ PB solution), and DMF $(50 \mu \mathrm{L}) . \mathrm{PB}, \mathrm{pH}=7.4$, was added such that the total reaction volume was $986 \mu \mathrm{L}$. This reaction was run in triplicate.

An initial timepoint $(100 \mu \mathrm{L})$ was removed from the reaction solution prior to polymerization. Polymerizations were run, processed, and analyzed as stated in polymerization one. The recovered yield of the photocatalyst was $8.5 \mathrm{mg} \pm 0.3 \mathrm{mg}$ compared to a theoretical yield of $6.8 \mathrm{mg}$, or $125 \% \pm 4 \%-$ suggesting residual buffer components were present. Upon dissolution of the residual photocatalyst in organic solvents, the insoluble buffer salts that accompanied the photocatalyst and increased the theoretical yield were visually apparent. SEC analysis showed that the remaining $p(E Y-N I P A A m)$ did not contain any detectable $p(D M A)$ (Figure S22).

The final lyophilized photocatalyst was dissolved in PB $(300 \mu \mathrm{L})$ and the solution was allowed to sit in the dark for 1 week to recover any pink color. Afterwards, the UV-vis absorbance spectrum showed minimal absorbance of the $p$ (EY-NIPAAm), approximately $1 / 10^{\text {th }}$ of what would be expected for the theoretical amount of photocatalyst recovered. The permanent photobleaching suggests that under these polymerization conditions there were changes to the structure of the photocatalyst which led to loss of photocatalytic activity. 


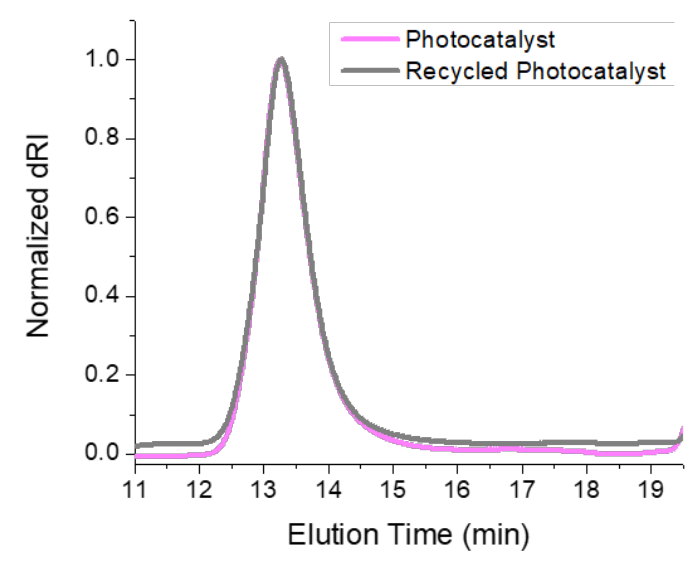

Figure S22: SEC trace of $p(E Y-N I P A A m)$ photocatalyst initially and after three recycling cycles 
Maleimide Functional Chain Transfer Agent (CTA) Synthesis

Scheme S4: Reaction scheme showing synthesis of maleimide-terminated CTA for attachment to BSA.

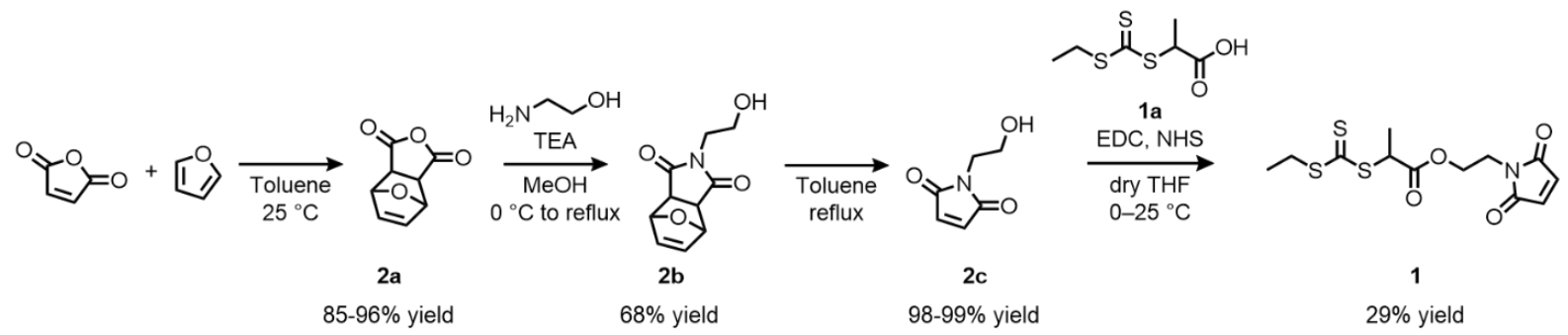

4,10-Dioxatricyclo[5.2.1. $0^{2,6}$ ]dec-8-ene-3,5-dione, 2a.

Maleic Anhydride (10.0277 g, $0.102261 \mathrm{mmol})$, furan $(15.0 \mathrm{~mL}, 0.206 \mathrm{mmol})$, and toluene $(15.0 \mathrm{~mL})$ were combined in a closed round bottomed flask. The reaction mixture was stirred for 3 days at room temperature. The crystals in the reaction mixture were collected, washed with petroleum ether, and dried under vacuum. (16.2 $\mathrm{g}, 85-96 \%$ yield).

${ }^{1} \mathrm{H} \mathrm{NMR}\left(400 \mathrm{MHz}, \mathrm{CDCl}_{3}\right) \delta: 6.60(\mathrm{~s}, 2 \mathrm{H}), 5.48(\mathrm{~s}, 2 \mathrm{H}), 3.20(\mathrm{~s}, 2 \mathrm{H})$

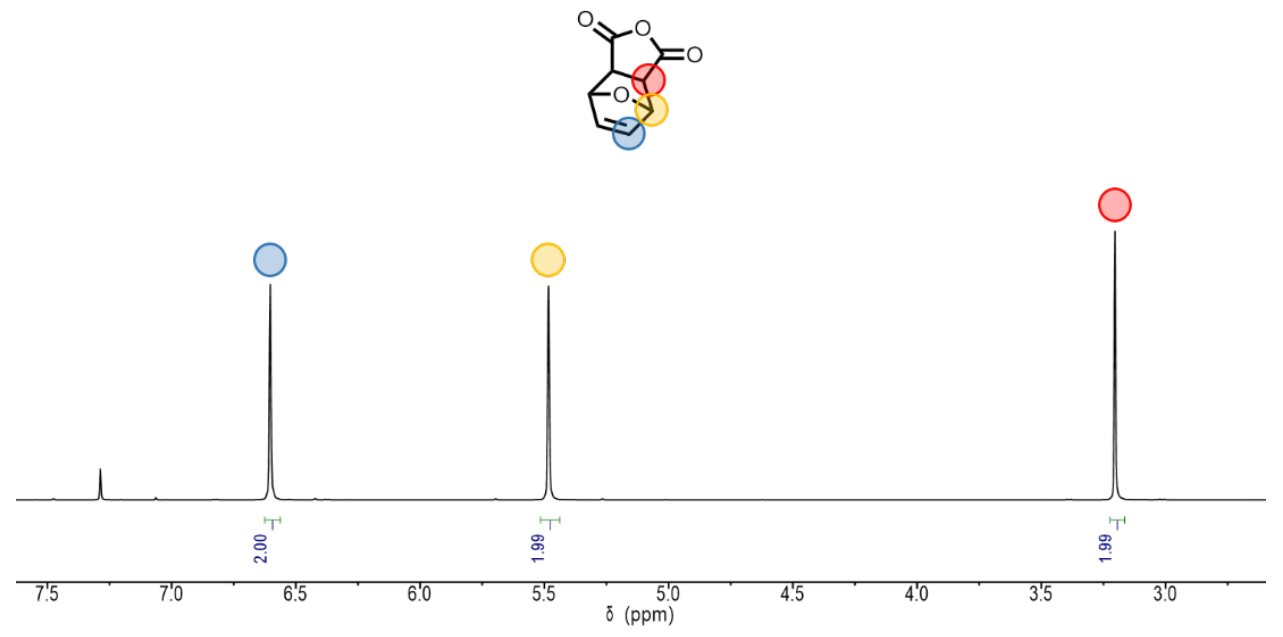

Figure S23: ${ }^{1} H$ NMR spectrum of 4,10-dioxatricyclo[5.2.1.0 $\left.{ }^{2,6}\right]$ dec-8-ene-3,5-dione, $2 a$. 
4-(2-Hydroxyethyl)-10-oxa-4-azatricyclo[5.2.1.0 2,6]dec-8-ene-3,5-dione, $\mathbf{2 b .}$

2a (4.0009 g, $24.083 \mathrm{mmol}$ ) was dissolved in methanol $(80 \mathrm{~mL})$. A solution of ethanolamine (1.46 mL, 24.1 $\mathrm{mmol})$, TEA $(3.40 \mathrm{~mL}, 24.4 \mathrm{mmol})$, and methanol $(20.0 \mathrm{~mL})$ was added dropwise to the stirring solution on ice. After addition, the reaction mixture was stirred for $5 \mathrm{~min}$ on ice before the ice bath was removed and the solution came to room temperature. The reaction was then heated under reflux conditions for $20 \mathrm{~h}$. The reaction was cooled to room temperature, and the volume was reduced slightly by rotary evaporation to induce crystal formation. The crystals were collected and rinsed with isopropyl alcohol $(3.44 \mathrm{~g}, 68 \%$ yield).

${ }^{1} \mathrm{H} \mathrm{NMR}\left(400 \mathrm{MHz}, \mathrm{CDCl}_{3}\right) \delta: 6.55(\mathrm{~s}, 2 \mathrm{H}), 5.31(\mathrm{~s}, 2 \mathrm{H}), 3.79(\mathrm{~m}, 2 \mathrm{H}), 3.74(\mathrm{~m}, 2 \mathrm{H}), 2.92(\mathrm{~s}, 2 \mathrm{H}), 2.21(\mathrm{bs}, 1 \mathrm{H})$

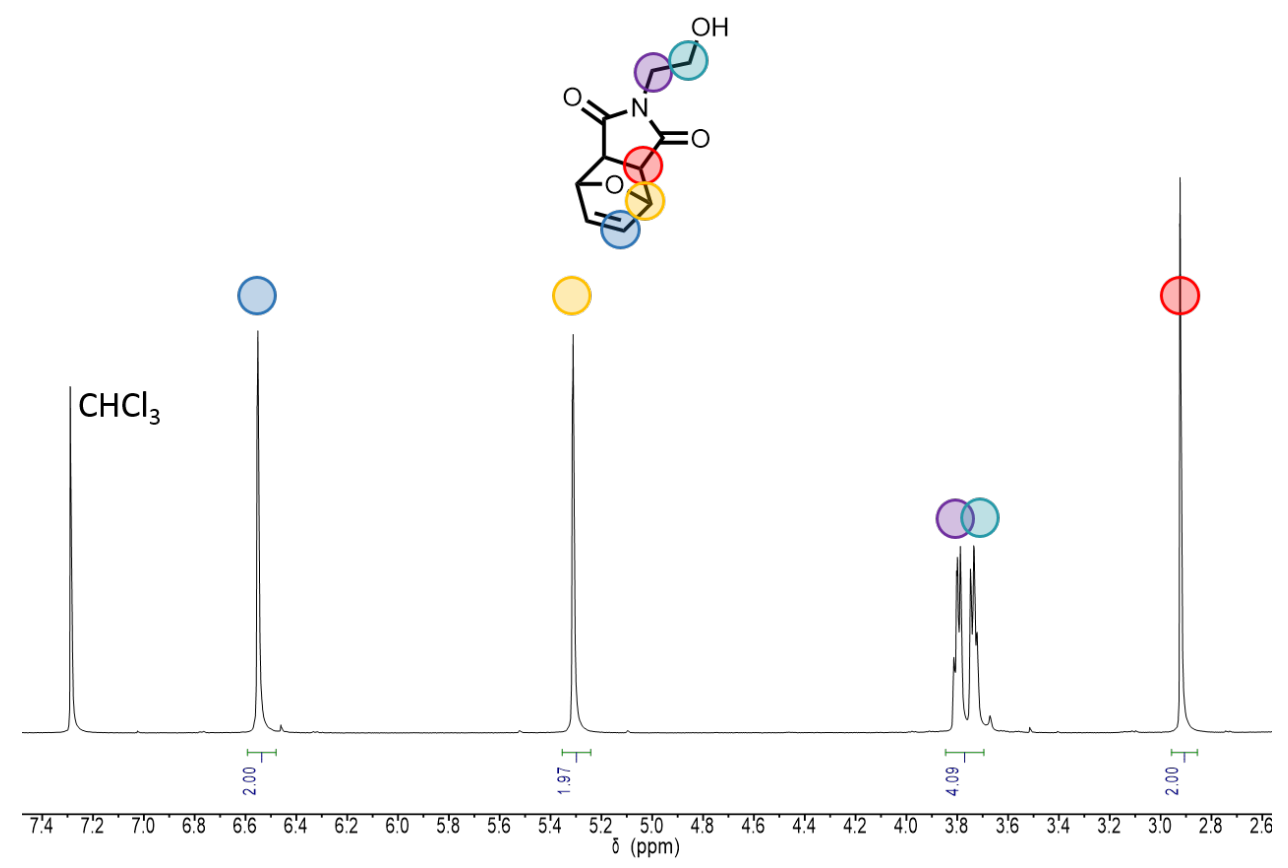

Figure S24: ${ }^{1} \mathrm{H}$ NMR spectrum of 4-(2-hydroxylethyl)-10-oxa-4-azatricyclo[5.2.1.0 $\left.{ }^{2,6}\right]$ dec-8-ene-3,5-dione, $2 b$. 


\section{4-(2-Hydroxyethyl)maleimide, 2c.}

2b (1.0019 g, $4.7892 \mathrm{mmol})$ was refluxed in toluene $(10.0 \mathrm{~mL})$ with a short, open reflux condenser until a minimal amount of starting material was left $(24 \mathrm{~h})$. The reaction mixture was transferred to a tared vial, and the reaction vessel was rinsed once with a minimal amount of hexanes. The reaction mixture was cooled to room temperature, and residual solvent was removed to leave white crystals (663 mg, 98-99\% yield).

${ }^{1} \mathrm{H}$ NMR $\left(400 \mathrm{MHz}, \mathrm{CDCl}_{3}\right) \delta: 6.76(\mathrm{~s}, 2 \mathrm{H}), 3.80(\mathrm{~m}, 2 \mathrm{H}), 3.76(\mathrm{~m}, 2 \mathrm{H})$

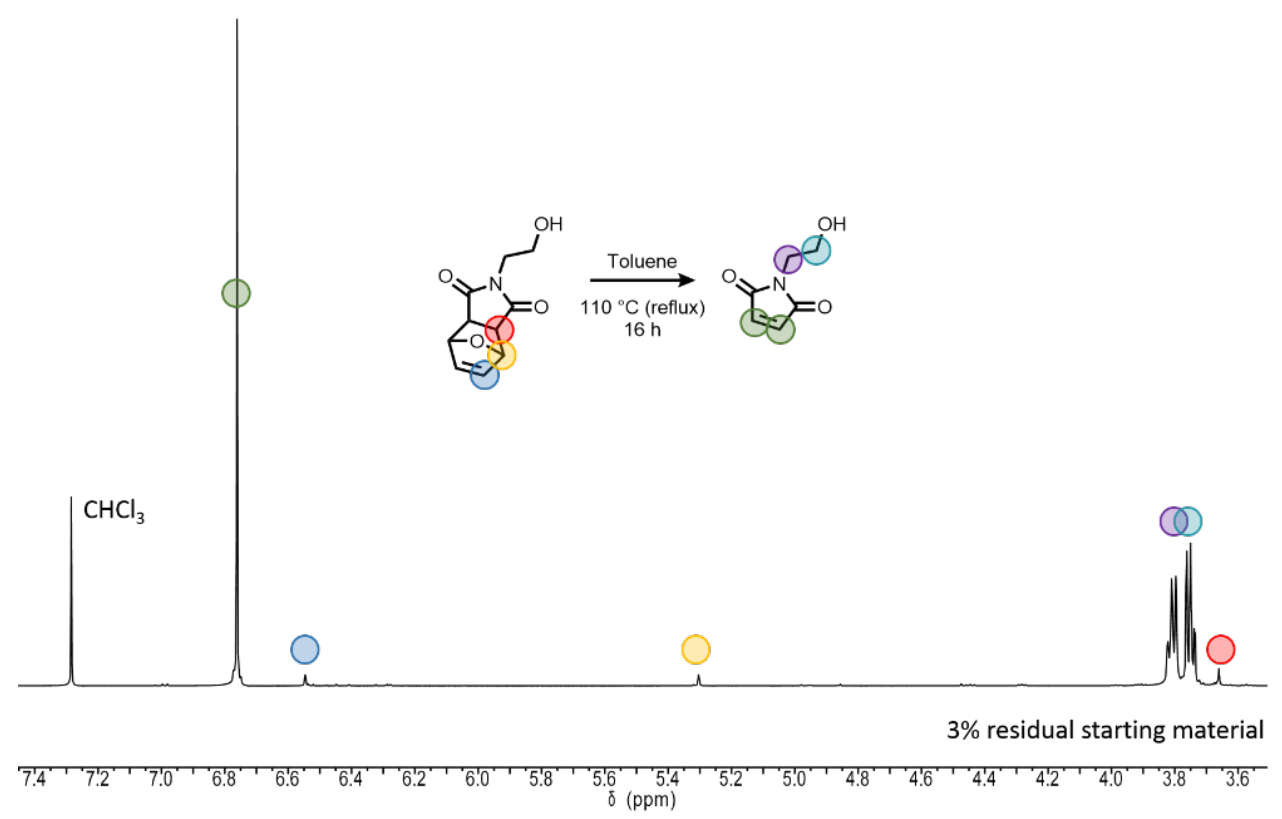

Figure S25: ${ }^{1} H$ NMR spectrum of 4-(2-hydroxyethyl)maleimide, $\mathbf{2 c}$.

2-(((Ethylthio)carbonothioyl)thio)propanoate-4-(2-hydroxyethylmaleimide) 1.

1a $(504.8 \mathrm{mg}, 2.400 \mathrm{mmol})$ was dissolved in dry THF $(10.0 \mathrm{~mL})$ with $N$-hydroxysuccinimide $(825.0 \mathrm{mg}$, $7.168 \mathrm{mmol}$ ), and the solution was sparged with argon. This solution was added via addition funnel to a sparged, 25-mL Schlenk flask in an ice bath containing a suspension of EDC. $\mathrm{HCl}(2.3194 \mathrm{~g}, 12.099 \mathrm{mmol})$ and dry THF (10.0 mL). The reaction mixture was stirred for $1.5 \mathrm{~h}$ prior to dropwise addition of solution $\mathbf{2 c}$ $(1.0084 \mathrm{~g}, 7.1452 \mathrm{mmol})$ and $\mathrm{N}, \mathrm{N}$-diisopropylethylamine $(1.24 \mathrm{~mL}, 7.12 \mathrm{mmol})$ in THF $(10.0 \mathrm{~mL})$. The reaction was stirred overnight $(>16 \mathrm{~h})$ and washed with distilled water $(10.0 \mathrm{~mL} \times 3)$ and brine $(20.0 \mathrm{~mL} \times$ 1). The organic layer was dried with anhydrous $\mathrm{MgSO}_{4}$, and the volume was reduced by rotary evaporation. The product was purified by column chromatography (eluent 90:10 hexanes:ethyl acetate) ( $231 \mathrm{mg}, 29 \%$ yield).

${ }^{1} \mathrm{H} \mathrm{NMR}\left(600 \mathrm{MHz}, \mathrm{CDCl}_{3}\right) \delta: 6.75(\mathrm{~s}, 2 \mathrm{H}), 4.81(\mathrm{q}, 1 \mathrm{H}), 4.33(\mathrm{~m}, 2 \mathrm{H}), 3.85(\mathrm{~m}, 2 \mathrm{H}), 3.37(\mathrm{q}, 2 \mathrm{H}), 1.61(\mathrm{~d}, 3 \mathrm{H})$, $1.38(\mathrm{t}, 3 \mathrm{H})$

${ }^{13} \mathrm{C}$ NMR $\left(125 \mathrm{MHz}, \mathrm{CDCl}_{3}\right) \delta: 221.66,170.93,170.23,62.53,47.54,36.75,31.49,16.71,12.93$

ESI: $\left[\mathrm{M}+\mathrm{Na}^{+}\right]_{\text {exp }}=356.0038 \mathrm{Da},\left[\mathrm{M}+\mathrm{Na}^{+}\right]_{\text {theo }}=356.0055 \mathrm{Da},\left[\mathrm{M}+\mathrm{H}^{+}\right]_{\mathrm{exp}}=334.0232 \mathrm{Da},\left[\mathrm{M}+\mathrm{H}^{+}\right]_{\text {theo }}=$ $334.0236 \mathrm{Da}$ 


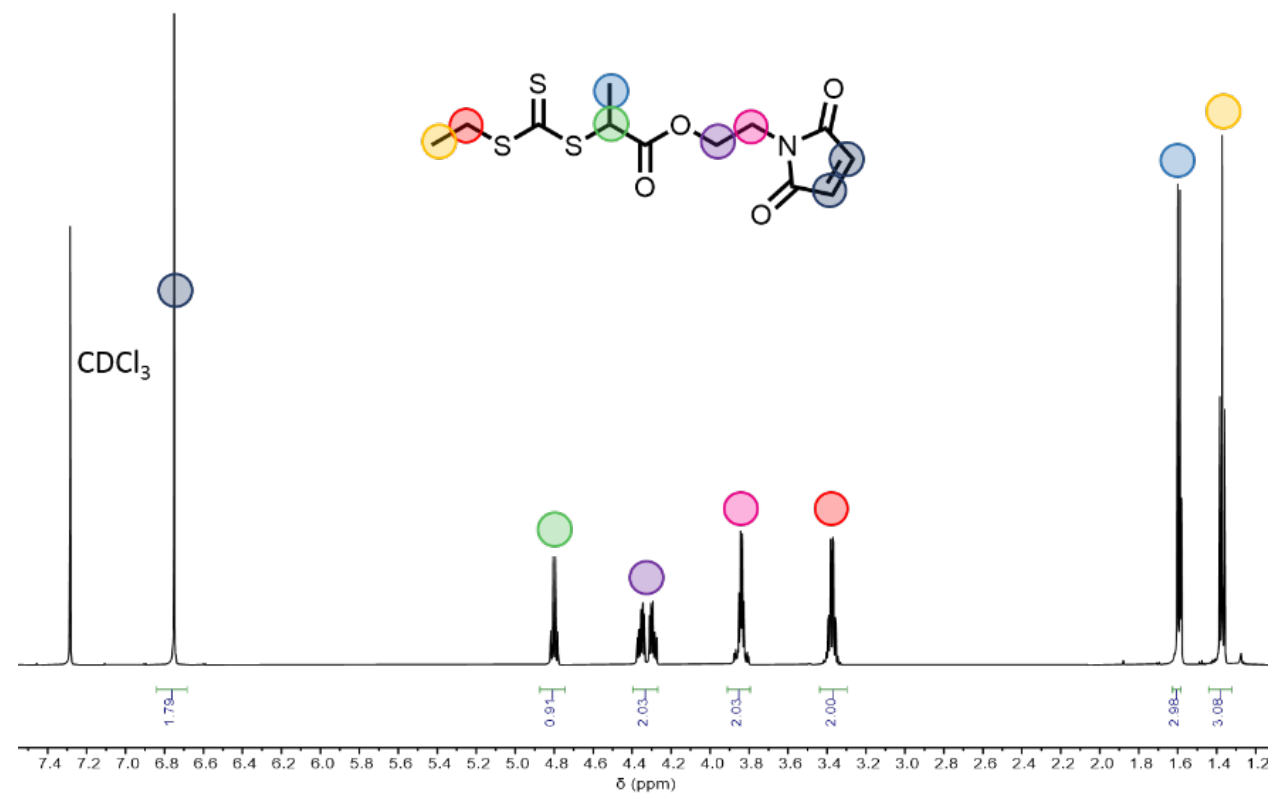

Figure S26: ${ }^{1} \mathrm{H}$ NMR spectrum of 2-(((ethylthio)carbonothioyl)thio)propanoate-4-(2hydroxyethylmaleimide), 1.
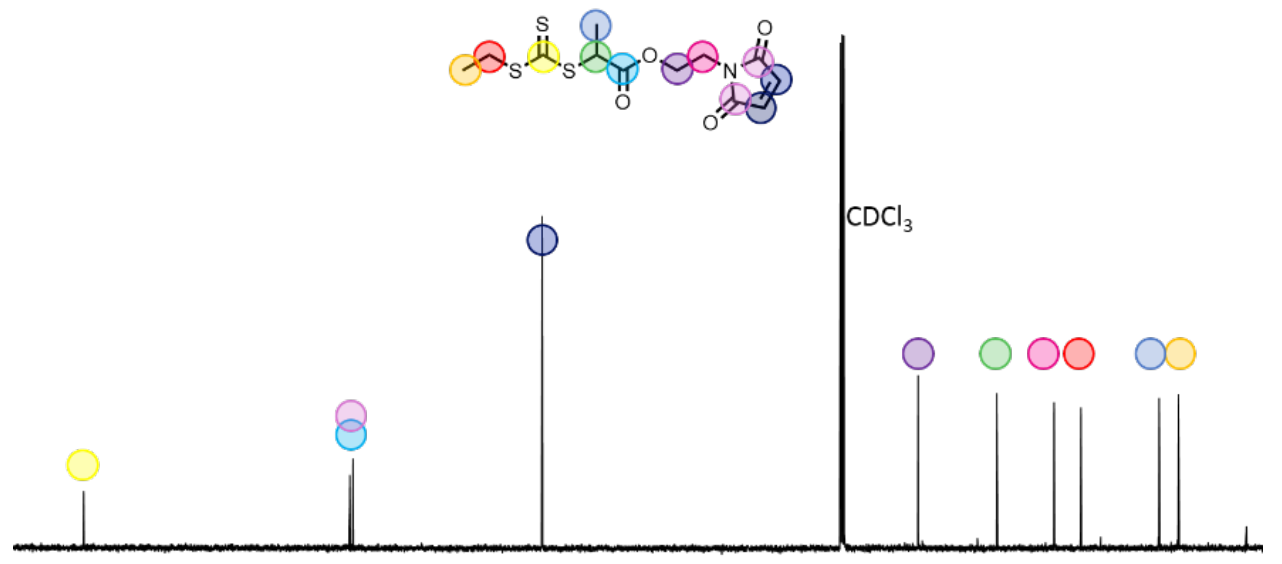

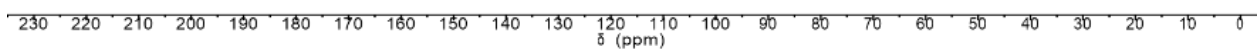

Figure S27: ${ }^{13} \mathrm{C}$ NMR spectrum of 2-(((ethylthio)carbonothioyl)thio)propanoate-4-(2hydroxyethylmaleimide), 1. 


\section{CTA Attachment to Bovine Serum Albumin (BSA) Protein}

\section{Quantification of CTA Attachment}

Table S6: Attachment of CTA 1 to BSA under different reaction conditions

\begin{tabular}{lllll}
\hline & & & $\begin{array}{l}\text { Cysteine } \\
\text { Addition } \\
\text { to } \\
\text { Quench } \\
\text { [BSA] : [CTA] : [Cysteine] }\end{array}$ & $\begin{array}{l}\text { Average } \\
\text { Number } \\
\text { of CTAs } \\
\text { per }\end{array}$ \\
\hline $1: 20: 0^{*}$ & $\begin{array}{l}\text { Time } \\
\text { (h) }\end{array}$ & pH & Reaction & \begin{tabular}{l} 
Protein \\
\hline $1: 20: 0^{*}$
\end{tabular} \\
\hline $1: 5: 10$ & 4 & 7.4 & No & 10 \\
\hline $1: 2: 4$ & 1 & 7.4 & No & 9 \\
\hline $1: 2: 4$ & 1 & 7 & Yes & 4 \\
\hline
\end{tabular}

Reactions were carried out as described below on a smaller scale (200 mg of BSA). Reactions denoted with

* were conducted in a Schlenk flask and purged with argon. The average number of CTAs per protein was based on MALDI-ToF spectra.

Bovine Serum Albumin (BSA, $2.0013 \mathrm{~g}, 0.030111 \mathrm{mmol}$ ) was dissolved in $100 \mathrm{mM}, \mathrm{pH}=6.5 \mathrm{~PB}(140 \mathrm{~mL})$. CTA 1 (20.0 mg, $0.0599 \mathrm{mmol})$ was dissolved in a minimal amount of DMSO (800 $\mu \mathrm{L})$ and added dropwise to the protein solution. Additional DMSO $(200 \mu \mathrm{L})$ was added to transfer residual CTA solution to the reaction mixture. The reaction was homogenized and then placed on a shaker plate for $1 \mathrm{~h}$. The reaction was quenched with a solution of L-cysteine hydrochloride $(19.0 \mathrm{mg}, 0.120 \mathrm{mmol})$ in PB $(10 \mathrm{mg} / \mathrm{mL})$. The mixture sat for $15 \mathrm{~min}$, and then it was dialyzed against $\mathrm{DI} \mathrm{H}_{2} \mathrm{O}(13 \mathrm{~L}$ ) for $24 \mathrm{~h}$ (Spectrum $10 \mathrm{kDa}$ cutoff regenerated cellulose tubing). The water was changed once after approximately $16 \mathrm{~h}$. After dialysis, the mixture was lyophilized to remove water and stored at $4{ }^{\circ} \mathrm{C}$ until use $(1.89 \mathrm{~g}, 95 \%$ yield).

The average number of CTA moieties per BSA was determined to be 1.16 by observing the absorbance of the moiety at $309 \mathrm{~nm}$ and comparing it to the absorbance assay of CTA 1a (vide supra). Overlaid MALDI spectra of BSA and CTA-functionalized BSA (BSA-CTA) indicate that the CTA was directly attached to the protein, and that, on average, approximately 1 CTA was attached to each protein. A concentration of roughly 1.1 CTAs per protein was assumed for polymerizations grafting from the protein. 


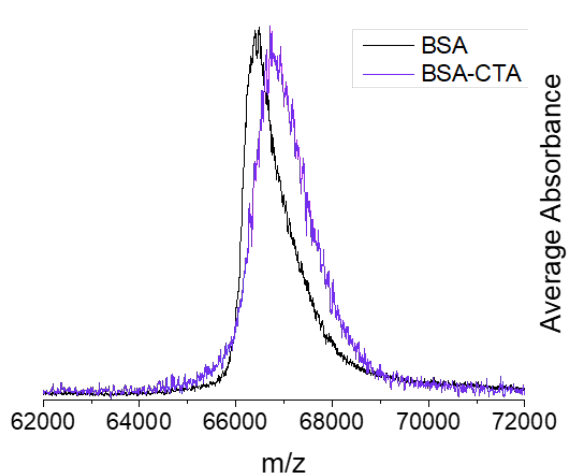

1 CTA per protein

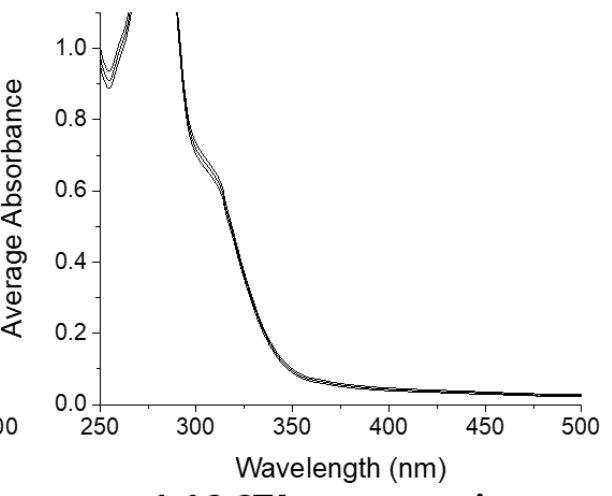

1.16 CTAs per protein

Figure S28: MALDI-ToF spectra of BSA before and after attachment of the CTA (left) and UV-vis absorbance spectra of BSA after attachment of the CTA (right). The absorbance of the BSA macroCTA was measured in quadruplicate and the average absorbance was plotted above. The lines above and below the central absorbance spectra indicated the error in those measurements.

\section{BSA-CTA Activity}

Protein solutions of both BSA and BSA-CTA $(0.25 \mathrm{mM})$ were made in $\mathrm{pH} 7.4100 \mathrm{mM}$ PB. Each protein solution $(25 \mu \mathrm{L})$ was combined with 4-nitrophenyl acetate $(5 \mu \mathrm{L}, 10 \mathrm{mM})$ in acetonitrile and $\mathrm{PB} \mathrm{pH} 8$ $(470 \mu \mathrm{L}, 100 \mathrm{mM})$. The solutions were incubated at room temperature for 20 min and centrifuged for 5 min at $6000 \mathrm{rpm}$. The absorbance at $405 \mathrm{~nm}$ was measured $35 \mathrm{~min}$ after addition of the 4NPA to evaluate activity. Activity measurements were taken in quadruplicate.

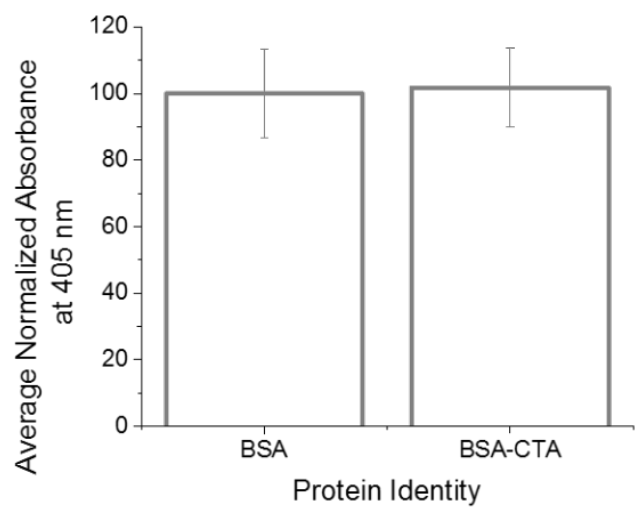

Figure S29: Activity of BSA prior to and after attachment of the CTA.

\section{Protein Digestion and Sequence Analysis}

The protein was digested, and the sequence was analyzed to determine the placement and concentration of the CTA on different amino acid residues (vide supra). The sequence used for analysis was taken from UniProt (P02769) and included below. The crystal structure was from the protein data bank (4F5S). ${ }^{5}$ After digestion and analysis using nano-liquid chromatography tandem mass spectrometry, 56 percent of the theoretical sequence was detected (highlighted in green, Figure S30). Functionalization was detected on 12 different amino acids: seven cysteine residues (C) and five lysine residues (K). The free thiol (C58) was the most highly tagged amino acid, as expected. The top ten most abundantly tagged amino acids are 
shown in Figure S31, along with their functionalization percentages. Amino acids which do not have a label showing percentage, or are not shown, comprise less than $1 \%$ of the detected functionalized residues.

BSA Canonical Sequence:

MKWVTFISLLLLFSSAYSRGVFRRDTHKSEIAHRFKDLGEEHFKGLVLIAFSQYLQQCPFDEHVKLVNELTEFAKTCVADE SHAGCEKSLHTLFGDELCKVASLRETYGDMADCCEKQEPERNECFLSHKDDSPDLPKLKPDPNTLCDEFKADEKKFWGK YLYEIARRHPYFYAPELLYYANKYNGVFQECCQAEDKGACLLPKIETMREKVLASSARQRLRCASIQKFGERALKAWSVA RLSQKFPKAEFVEVTKLVTDLTKVHKECCHGDLLECADDRADLAKYICDNQDTISSKLKECCDKPLLEKSHCIAEVEKDAIP ENLPPLTADFAEDKDVCKNYQEAKDAFLGSFLYEYSRRHPEYAVSVLLRLAKEYEATLEECCAKDDPHACYSTVFDKLKHL VDEPQNLIKQNCDQFEKLGEYGFQNALIVRYTRKVPQVSTPTLVEVSRSLGKVGTRCCTKPESERMPCTEDYLSLILNRLC VLHEKTPVSEKVTKCCTESLVNRRPCFSALTPDETYVPKAFDEKLFTFHADICTLPDTEKQIKKQTALVELLKHKPKATEEQ LKTVMENFVAFVDKCCAADDKEACFAVEGPKLVVSTQTALA

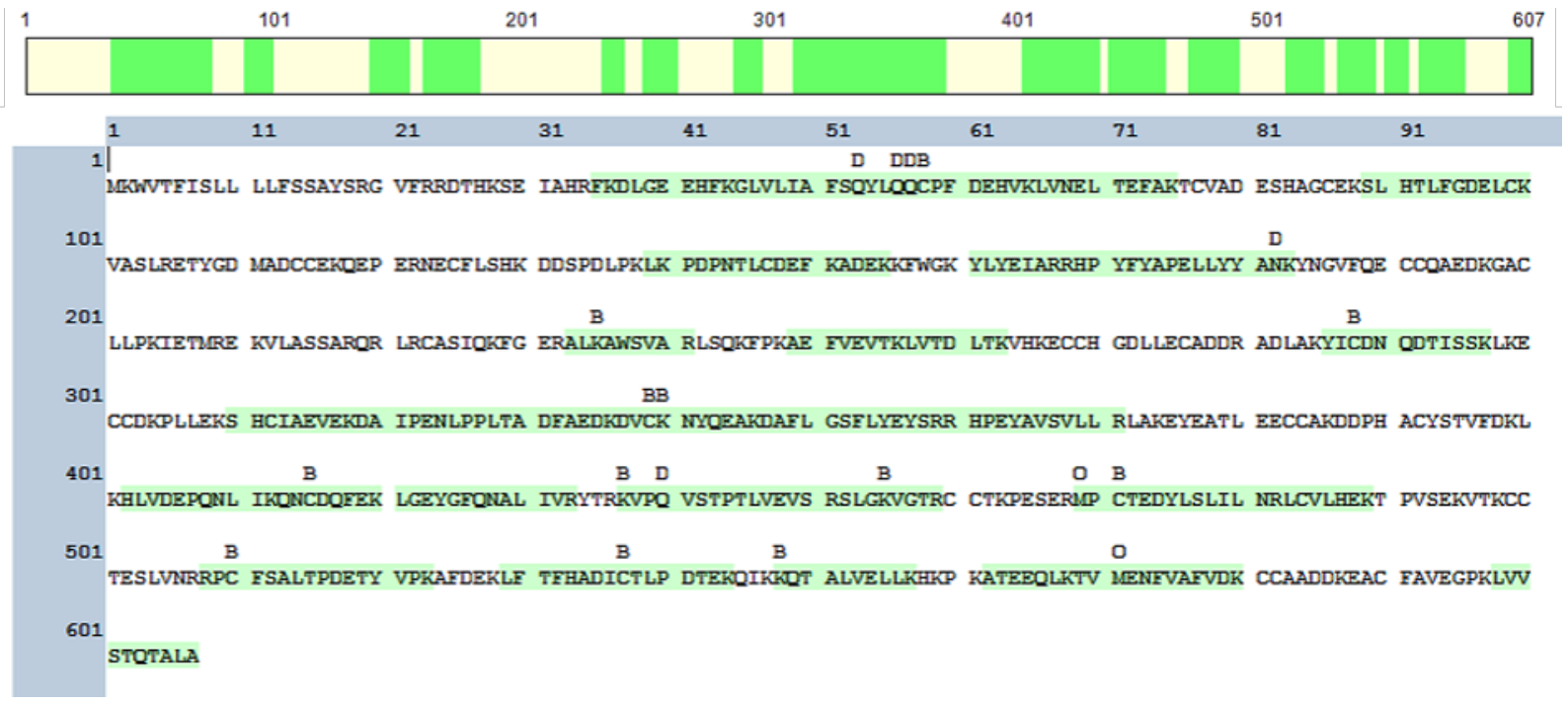

Figure S30: Sequence of BSA protein showing portions of the sequence which were detected (56\%). Amino acids which have a " $B$ " above them had detectable attachment of the CTA. Amino acids with a " $D$ " denote deamidation and amino acids with an " $O$ " denote oxidation. 


\section{Modification of Amino Acids}

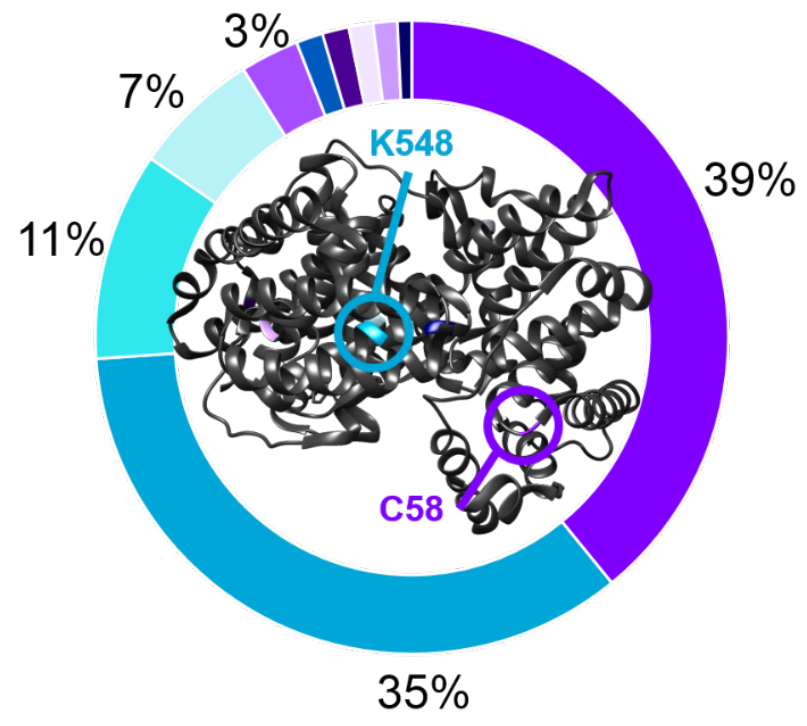

Figure S31: Chart showing the percent functionalization of the 10 most abundantly tagged cysteine (C), and lysine $(K)$ residues. Amino acids which are not labeled with a percentage or not shown comprise less than 1 percent of the detected, functionalized species.

\section{Polymerization from Protein}

A general polymerization from the protein was carried out as follows. Certain variables may have been changed as denoted. P(EY-NIPAAm) $\left(14.0 \mathrm{mg}, 3.00 \times 10^{-5} \mathrm{mmol}\right)$ was combined with $\mathrm{pH}=7.4 \mathrm{~PB}(300 \mu \mathrm{L})$ and stored in the refrigerator $\left(10{ }^{\circ} \mathrm{C}\right)$ to solubilize overnight. The polymeric photocatalyst was then combined with BSA-CTA $\left(271.9 \mathrm{mg}, 4.500 \times 10^{-3} \mathrm{mmol}\right)$, assuming that on average there are approximately 1.1 CTAs per 66,463 Da protein, i.e., the molecular weight per CTA was 60,421. DMA ( $93 \mu \mathrm{L}, 0.90 \mathrm{mmol}$, $0.50 \mathrm{M}$ ), AscA (0.396 mg, $0.00225 \mathrm{mmol}, 39.6 \mu \mathrm{L}$ of a $10 \mathrm{mg} / \mathrm{mL}$ PB solution), DMAP (0.551 mg, $4.50 \times 10^{-}$ ${ }^{3} \mathrm{mmol}, 55.1 \mu \mathrm{L}$ of a $10 \mathrm{mg} / \mathrm{mL}$ PB solution), and DMF (50 $\left.\mu \mathrm{L}\right)$ were added to the BSA-CTA solution. PB, $\mathrm{pH}$ $=7.4$, was added such that the total reaction volume was $1.8 \mathrm{~mL}$.

After combining all components of the reaction, the solution was mixed and nine aliquots $(200 \mu \mathrm{L})$ were removed and placed in individual, 1.5-mL Eppendorf containers. The samples were placed in a holder and placed in the green light reactor. Polymerization was initiated by turning on the light. Two fans and an ice bath were used to limit heating. Samples were irradiated for $4 \mathrm{~h}$. One Eppendorf vial was removed every $30 \mathrm{~min}$ and opened to air to halt polymerization.

The $200 \mu \mathrm{L}$ aliquot was divided for analysis as follows:

(1) ${ }^{1} \mathrm{H}$ NMR: The polymerization aliquot $(50 \mu \mathrm{L})$ was combined with DMSO- $d_{6}(\sim 0.45 \mathrm{~mL})$ for analysis.

(2) SEC: The polymerization aliquot $(70 \mu \mathrm{L})$ was combined with PB $(30 \mu \mathrm{L})$, heated in a water bath a $37^{\circ} \mathrm{C}$ for 15-30 min, and filtered through a warm filter to remove precipitated p(EY-NIPAAm). DI water (100 $\mu \mathrm{L}$, $37{ }^{\circ} \mathrm{C}$ ) was used to rinse any remaining soluble polymer out of the filter. The filtered samples were combined with $1 \mathrm{~mL} \mathrm{pH} 11$ water, boiled for $10 \mathrm{~min}$, and allowed to hydrolyze at room temperature for 5 
days. Finally, samples were frozen in liquid nitrogen and lyophilized prior to addition of $0.5 \mathrm{~mL}$ DMAc. Samples were filtered immediately to limit solvation of residual salts or peptides from the PB. Samples sat overnight prior to SEC analysis.

(3) Activity: The polymerization aliquot $(2.8 \mu \mathrm{L})$ was combined with $100 \mathrm{mM} \mathrm{PB}, \mathrm{pH} 7.4(22.2 \mu \mathrm{L})$, to make $25 \mu \mathrm{L}$ of a $0.25 \mathrm{mM}$ protein solution. To this was added $10 \mathrm{mM}$ 4-nitrophenyl acetate $(5 \mu \mathrm{L})$ in acetonitrile and $100 \mathrm{mM} \mathrm{PB}, \mathrm{pH} 8(470 \mu \mathrm{L})$. The solution was incubated at room temperature for $20 \mathrm{~min}$ and then centrifuged for $5 \mathrm{~min}$ at $6000 \mathrm{rpm}$. The absorbance at $405 \mathrm{~nm}$ was measured to evaluate activity $35 \mathrm{~min}$ after addition of the 4NPA. Activity measurements were taken in quadruplicate.

(4) SDS-PAGE: The polymerization aliquot $(6.6 \mu \mathrm{L})$ was diluted with PB $(993.4 \mu \mathrm{L})$ to make a $1 \mathrm{mg} / \mathrm{mL}$ protein solution. The $1 \mathrm{mg} / \mathrm{mL}$ protein solution $(30 \mu \mathrm{L})$ was combined with denaturing buffer and boiled for $10 \mathrm{~min}$. The protein solution $(10 \mu \mathrm{L})$ was placed in each well for SDS-PAGE analysis. The gels were run for $45 \mathrm{~min}$ at $180 \mathrm{~V}$ and the proteins were stained using a Coomassie blue dye.

The same conditions were used for polymerizing NMO from BSA-CTA ([NMO] : [CTA] : [p(EY-NIPAAm)] : [DMAP] : [AscA] was 200:1:0.01:1:0.5).

\section{Control Polymerization of DMA with EY from Protein}

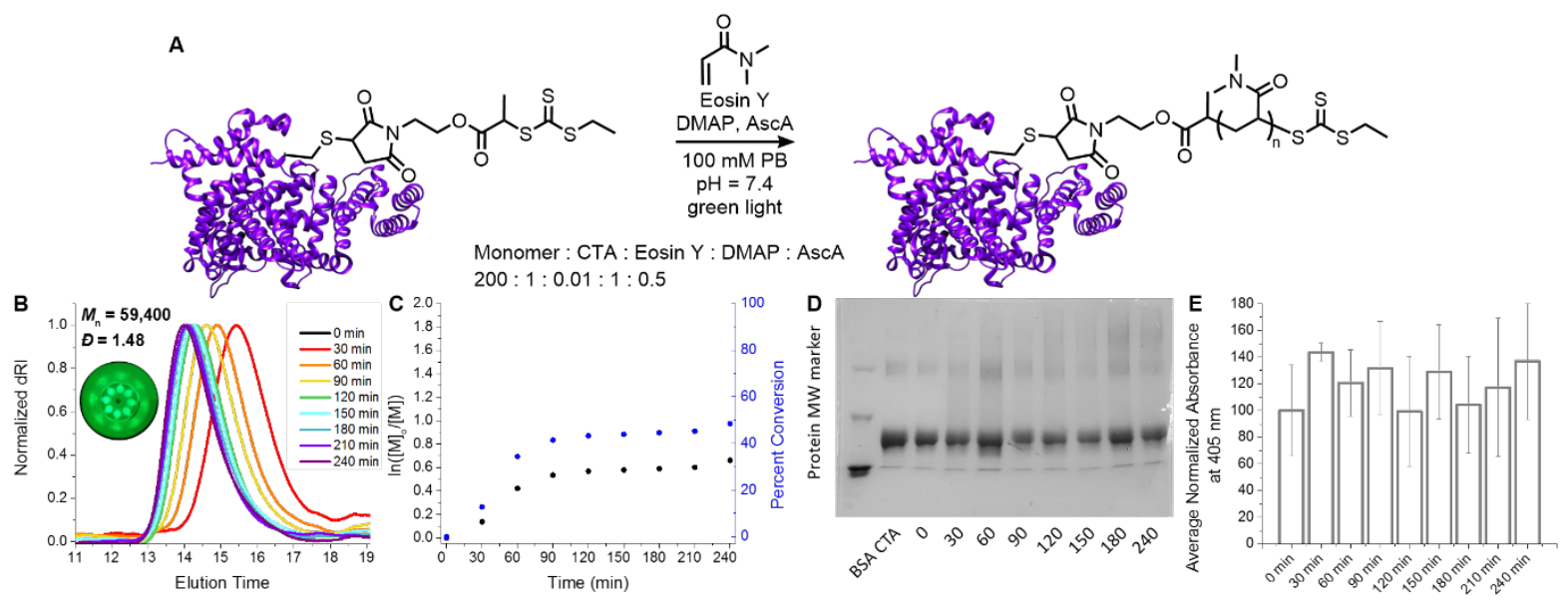

Figure S32: $M W$ and kinetic data of the polymerization grafting DMA from the surface of BSA using EY

\section{References}

(1) Keller, A.; I. Nesvizhskii, A.; Kolker, E.; Aebersold, R. Empirical Statistical Model To Estimate the Accuracy of Peptide Identifications Made by MS/MS and Database Search. Anal. Chem. 2002, 74, 5383-5392.

(2) I. Nesvizhskii, A.; Keller, A.; Kolker, E.; Aebersold, R. A Statistical Model for Identifying Proteins by Tandem Mass Spectrometry. Anal. Chem. 2003, 75, 4646-4658.

(3) Arrington, K. J.; Matson, J. B. Assembly of a Visible Light Photoreactor: An Inexpensive Tool for Bottlebrush Polymer Synthesis via Photoiniferter Polymerization. Polym. Chem. 2017, 8, 74527456.

(4) Kovaliov, M.; Allegrezza, M. L.; Richter, B.; Konkolewicz, D.; Averick, S. Synthesis of Lipase Polymer 
Hybrids with Retained or Enhanced Activity Using the Grafting-from Strategy. Polymer. 2018, 137, 338-345.

(5) Bujacz, A. Structures of Bovine, Equine and Leporine Serum Albumin. Acta Crystallogr. Sect. D 2012, 68, 1278-1289. 